\title{
A Novel Hybrid Network Optimization Model for Printed Circuit Boards Recycling: A Circular Economy Perspective
}

ABDULLAH YILDIZBASI ( $\sim$ abdullahyildizbasi@gmail.com )

Ankara Yildirim Beyazit University: Ankara Yildirim Beyazit Universitesi https://orcid.org/0000-00018104-3392

\section{Yağmur ARIOZ}

Ankara Yildirim Beyazit University: Ankara Yildirim Beyazit Universitesi

\section{Research Article}

Keywords: Circular Economy, Open-Loop Supply Chain, Closed-Loop Supply Chain, Mixed Integer Linear Programming, Sustainability, Printed Circuit Board

Posted Date: July 6th, 2021

DOI: https://doi.org/10.21203/rs.3.rs-157521/v1

License: (c) (i) This work is licensed under a Creative Commons Attribution 4.0 International License. Read Full License 


\title{
A Novel Hybrid Network Optimization Model for Printed Circuit Boards Recycling: A Circular Economy Perspective
}

\author{
Abdullah YILDIZBASI*, Yağmur ARIOZ \\ Department of Industrial Engineering, Ankara Yıldırım Beyazıt University, 06010 Ankara, Turkey \\ ayildizbasi@ybu.edu.tr \\ Department of Industrial Engineering, Ankara Yıldırım Beyazıt University, 06010 Ankara, Turkey \\ ariozyagmur@gmail.com
}

\begin{abstract}
Due to the rapid advances in technology, increasing consumption rates and continuously released new products lead to shorter product life cycles, putting the sustainability issue under the spotlight. This, in turn, creates an unmanageable amount of waste that needs immediate care. Electrical and electronic equipment is one of the major contributors to this waste given that millions of metric tons of electronic waste are generated across the world each year, and only an insignificant percentage of which is recycled. The recycling of printed circuit boards, which accounts for considerable monetary value in waste electrical and electronic equipment has long been ignored due to the serious challenges in collection, dismantling, and recycling processes. In this study, the open-loop and closed-loop supply chain involving circular economy objectives is designed in order to increase the recyclability of valuable metals including gold, silver, copper, and palladium. In this regard, a mixed-integer linear programming model is developed that aims at maximizing the profit from the flow in the supply chain network. The model was tested with actual data obtained from a printed circuit board firm in Turkey that aimed optimal distribution in its supply chain. The results reveal that the product/material flows, which have an impact on the revenues, were among the most important factors affecting profitability. Considering the circular economy objectives, the revenue obtained in the hybrid open-loop and closedloop supply chain is predominantly provided by the reuse and repair activities. In addition, the boundaries of the proposed model are tested with sensitivity analyses and the results are discussed extensively with conclusions on managerial implications.
\end{abstract}

Keywords: Circular Economy; Open-Loop Supply Chain; Closed-Loop Supply Chain; Mixed Integer Linear Programming; Sustainability; Printed Circuit Board

* Corresponding author.

E-mail addresses: ayildizbasi@ybu.edu.tr (Yıldızbası A.)

$\begin{array}{ll}\text { Abbreviations } & \\ \text { ANP } & \text { Analytical Network Process } \\ \text { CE } & \text { Circular Economy } \\ \text { EEE } & \text { Electrical and Electronic Equipment } \\ \text { GSCM } & \text { Green Supply Chain Management } \\ \text { WEEE } & \text { Waste Electrical and Electronic Equipment } \\ \text { LCA } & \text { Life Cycle Assesment } \\ \text { PCB } & \text { Printed Circuit Boards } \\ \text { WPCB } & \text { Waste Printed Circuit Boards } \\ \text { MINLP } & \text { Mixed Integer Linear Programming }\end{array}$




$\begin{array}{ll}\text { OF } & \text { Objective Function } \\ \text { PI } & \text { Performance Indicators } \\ \text { PV } & \text { Photovoltaic } \\ \text { RQ } & \text { Research Question }\end{array}$

\section{INTRODUCTION}

In recent years, environmental concerns, fast deterioration of natural resource and high levels of urbanization and industrialization have made electronic waste management in a way to have the lowest environmental impact and the highest economic utility more important (Deveci 2016). As an example to electronic wastes, electronic cards which are found in the structure of several electrical and electronic equipment are the building block of the fastest-growing source of waste in the world (Maisel et al. 2020). Until 2016, the world created 44.7 million metric tons of electronic waste, and only $20 \%$ was recycled properly (Baldé et al. 2017). Electronic waste is a substantial problem for the world due to both its environmental effect and its potential to form substances that are harmful to human health. Likewise, with a waste management approach involving recycling, consumption, collection, sorting and disposal of waste electrical and electronic equipment (WEEE), in developed countries, it is aimed to minimize the damages (Ismail and Marlia 2020).

One of the most striking examples of WEEE is waste printed circuit boards (WPCBs) (Jadhao et al. 2020). Because of WPCBs are included precious materials such as ferrum, copper, silver, gold and palladium, recycling of WPCB is focused mainly on the recovery of these materials (Awasti et al. 2017). Furthermore, WPCBs are contained hazardous materials in addition to valuable materials. Hazardous materials such as lead, mercury, arsenic, cadmium, selenium, chromium (+6) and flame retardant are threatened to human health and the environment since the waste of these products to gain the property of hazardous waste (Özkan 2018). Hence, recycling of WPCBs does not only protect the environment but provides the sustainability of resources also. Beside, WPCBs are found in the structure of every piece of electrical and electronic equipment and may have a large share in the circular economy. The supply chain of printed circuit boards (PCBs) which are the most fundamental form of electronic cards has been designed from production to consumption and from collection to recycling in the scope of circular economy (Wagner et al. 2019).

For management of electronic wastes with the help of more collaboration in the supply chain network, by creating a circular economy, economic utility may be increased, environmental impact may be brought down to desired levels, and new jobs and opportunities may be created in the social sense.

In this network, the second-hand materials that are obtained from the first dismantling of PCBs are sent to factories or various users for them to be reprocessed for selling in the internal market. This way, an open-loop supply chain is formed. The open-loop supply chain design provides different actors and alternative supply chain networks with materials that could be used for reproduction (Kalverkamp 2018; Ene and Öztürk 2014). Thus, open-loop network designs may be useful for some recycling methodologies. Departing from this point, in this study, a PCB supply chain network was examined with an open-loop network design. 
The second characteristic of the examined network is that it is an integrated closed-loop supply chain network that makes a contribution to the circular economy by using the raw materials obtained from recycling again in the same loop and reducing resource usage. That is, circular economy objectives are considered and integrated into the developed supply chain network. In the network, a framework that takes on and associates the 10R circular economy objectives is presented. Figure 1 depicts circular economy objectives and definitions. This shows a hierarchical construct that has colors varying from light to dark. While progressing from the R9 objective to the R0 objective, the strategic activity of the circular economy objectives increases (Potting et al. 2017).

\begin{tabular}{|c|c|c|c|c|}
\hline \multirow{2}{*}{$\begin{array}{l}\text { Circular } \\
\text { Economy }\end{array}$} & \multirow{2}{*}{$\begin{array}{c}\text { Smarter } \\
\text { Product Use } \\
\text { and } \\
\text { manufacture }\end{array}$} & REFUSE & RO & $\begin{array}{l}\text { Make product redundant by leaving its function or by supplying the same function with a } \\
\text { originally different product. }\end{array}$ \\
\hline & & RETHINK & R1 & Make product use more intensive (e.g. by putting multi-useful products on market). \\
\hline & & REDUCE & R2 & $\begin{array}{l}\text { To enhance, efficiency in product manufacture or use by depleting fewer natural } \\
\text { resources and materials. }\end{array}$ \\
\hline & & REUSE & R3 & $\begin{array}{l}\text { Reuse by another consumer of throw-away product which is still in good condition and } \\
\text { carries out its original function. }\end{array}$ \\
\hline & $\begin{array}{c}\text { Extand } \\
\text { Lifespan of }\end{array}$ & REPAIR & R4 & Renovation and maintenance of impaired product so it can beused with its original function. \\
\hline & its part & REFURBISH & R5 & Restore an out of date product and bring it until date. \\
\hline & & REMANUFACTURE & R6 & Use parts of throw-away product in a new product with the same function. \\
\hline & & REPURPOSE & R7 & Use throw-away product or its parts in a new product with a different function. \\
\hline Linear & Useful & RECYCLE & R8 & Process materials to get the same (high grade) or lower (low grade) quality \\
\hline Economy & of materials & RECOVER & R9 & Incineration of material with energy recovery. \\
\hline
\end{tabular}

Figure 1 Strategies of transitioning from linear economy to circular economy

Circular economy has emerged as an economic strategy involving both production processes and consumption, and it is a new sustainability and innovation-based production model where costs are minimized, and resource productivity and environmental benefit are maximized. Although circular economy is a relatively new topic, hundreds of firms in the world and in Turkey are developing business models and services compatible with a circular economy. A previous study Velenturf et al. (2019) suggested that the circular economy perspective that aims to preserve the value of products as long as possible should be embraced rather than the unproductive "take-do-dispose" economic model. Electronic waste, which is a part of a dynamic system position in circular economy, presents various opportunities. The benefits of circular economy may be listed as material optimization, waste disposal, energy savings, new income flows, improved stakeholder relations, brand reputation and risk mitigation (Baldé et al. 2017; Anna et al. 2019).

Integrating these objectives into electronic card network design provides a sustainable contribution to the circular economy due to its environmental, social and economic dimensions. Sustainability, which has three main aspects as social, environmental and economic aspects, is a way to use resources efficiently by considering the needs of future generations (Williams and Robinson 2020). 
In addition to this, circular economy provides a broader vision of sustainability by focusing on resource cycles for sustainability. While not every sustainability activity contributes to circularity, circular economy practices contribute to a more sustainable system (Hanumante et al. 2019).

The important point of the study is to analyze the effect that will be provided by recycling through actual data. In this context, this study focuses on the following research questions:

RQ 1: Network design for printed circuit boards recycling with the open-loop and closed-loop supply chain approach from the perspective of circular economy

RQ 2: What are the factors that affect profitability in the hybrid open-loop and closed-loop supply chain network developed over electronic card recycling? In other words, what are the effects of factors such as capacity, recycling ratios and customer demand in the scope of the costs and revenues in the proposed open-loop supply chain model on profitability?

Based on the specified research questions, the main purpose of this study is to design an open-loop supply chain and closed-loop supply chain networks towards recycling of electronic cards with the circular economy perspective (suppliers, manufacturers, customers, end users, recycling centers, collection centers and dismantler centers). Afterwards, a mixed-integer linear programming (MILP) model was developed through this network design, and the results were mathematically analyzed with actual data obtained from a PCB firm in Turkey. Moreover, the effects of factors such as demand, recycling ratios, transportation costs and facility capacities on profitability in the open-loop supply chain network constitute another significant part of the study. Additionally, analyses of different scenarios are important in terms of measuring the sensitivity of such models. For this reason, in the study, several parameters were kept in consideration, and scenario analyses with the combinations of these parameters are presented.

To the best of the authors' knowledge, there are few studies in the literature on the hybrid open-loop and closed-loop supply chain approach in recycling of electronic cards. Furthermore, most existing studies are on a theoretical level. This study has the quality to fill the gap in the literature in that it is not only focuses on an actual case but also discusses electronic card recycling. The network structure proposed by the study will provide significant contributions to the literature on circular economy in terms of being a source of inspiration for many different circular economy studies.

As the novelty of this study, although the circular economy is handled within a perspective its 10R targets were tested and investigated their economic and environmental effects in terms of analysis and applicability through open-loop and closed-loop network design used simultaneously on a real case study. From an originality aspect, despite the existence of the hybrid open-loop and closed-loop supply chain articles in the literature (Özceylan, E. (2016), Huysman, S et al. (2015), Larrain, M. et al.(2020), it is a pioneer study by reflecting the circular economy perspective on a real case.

The remainder of the article is structured as follows. In section 2, the literature review of the related study to three subsections is portrayed. A case study of the simultaneous optimization of the hybrid open-loop and closed-loop 
network design within the circular economy perpective is presented in Section 3. In section 4 the results of the model are presented. In section 5 the obtained solutions are discussed, the scenario analyses and managerial implications of the model design in terms of circular economy targets are presented. The final section concludes the article and suggestions for future studies related to research.

\section{LITERATURE REVIEW}

In relation to the open-loop recycling network design model developed by on circular economy perspective for recycling of PCBs, on the Scopus, ScienceDirect and ResearchGate databases, a search was carried out by using the key phrases "circular economy", "recycling”, “open-loop supply chain", "closed-loop suuply chain", "waste electric electronic equipment" and "printed circuit board", and the accessed articles were discussed in the relevant sections. Firstly, the articles that were thought to be related to the proposed study were classified, and then, 66 articles that had the quality to contribute to the study were determined and taken into analysis. The analyzed articles were grouped under 3 different titles, and it was aimed to find answers to the research questions. The operational steps in question are shown graphically in Figure 3. In this context, in the first part of the literature review, the concept of circular economy and related studies were discussed. In addition to the advantages and disadvantages of circular economy, potential problems encountered in practice and recommendations were analyzed under this title. At the second stage, studies conducted on open-loop and closed-loop supply chain were examined, and by focusing on examples of mathematical models, the infrastructure of the model to be developed was formed. In the third step, articles accessed as a result of the search made by using the key phrases of circular economy perspective and open-loop \& closed-loop supply chain were analyzed, and by determining the issues that would reveal the difference of the proposed study to other studies, it was aimed to emphasize the contribution of the study to the literature. Each section includes summary tables created based on the relevant key phrases, while the last section defines the research questions of the study based on the GAP analysis revealed as a result of the literature review.

With the literature review, in the scope of the CE, WEEE and open-loop supply chain, and closed-loop supply chain concepts answers will be sought for the questions of:

1- What types of studies were previously conducted in the literature, how methodologies were applied, how objectives were reached, what the related studies were and for which problem solutions were searched,

2- On which sectors and by using which methods studies were conducted,

3- How circular economy perspective was adapted to different sectors, especially the WEEE industry,

4- In which sectors and how the open-loop recycling approach was practiced,

5- How the concepts of open-loop and closed-loop supply chain networks were discussed together with a circular economy perspective and on which sectors studies were carried out. 


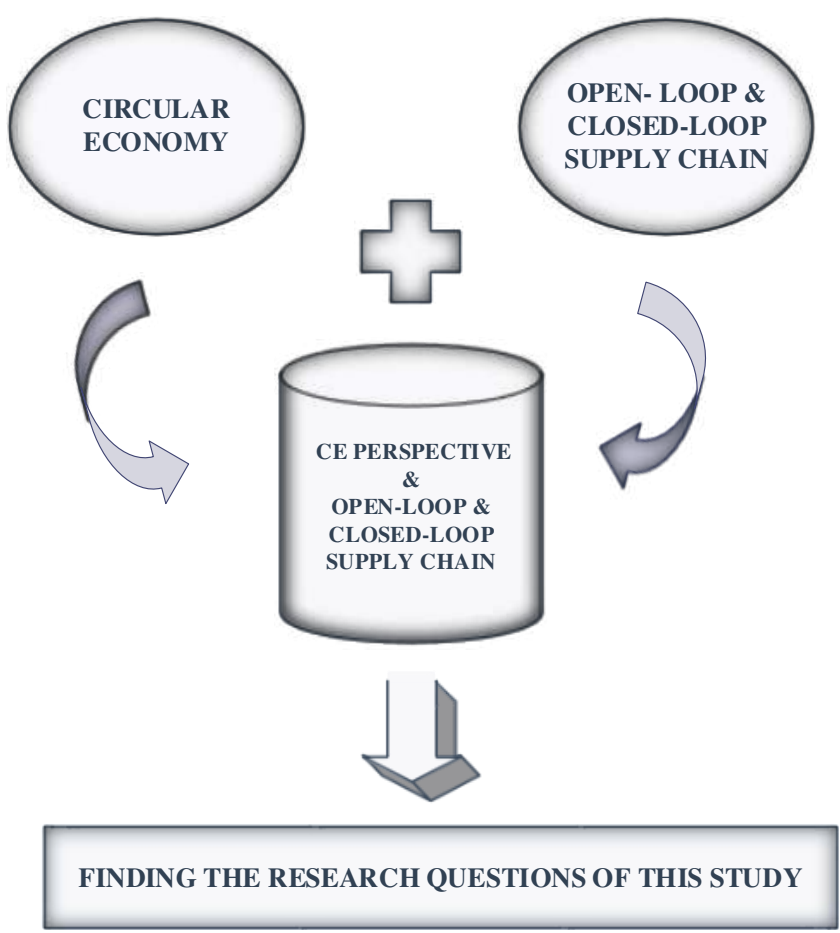

Figure 2 Filtering research area according to the literature review

\subsection{Literature Review on Circular Economy Studies}

In recent years, with environmental concerns and exhaustion of resources, the concept of circular economy has received the attention of several academicians, researchers and implementers .In this context, studies carried out on circular economy were comprehensively taken on, and the objectives and application areas of these studies are shown in Table 1. Accorsi et al. (2020) contributed to the literature by a study based on recycling with a proposal of a circular economy perspective depending on network design.

In the study where they emphasized the importance of circular economy in supply chains, Moktadir et al. (2018) reported that, with the help of sustainable production practices and circular waste management carried out at leather production industries, energy and material usage decreased, and resource usage was optimized.

Hanumante et al. (2019) emphasized that assessment of the systematic effects of circular economy on the global scale with a comprehensive perspective is an important instrument for transition to a sustainable future. For this purpose, the proposed a holistic model where the human, environment and industrial components were assessed together and examined the potential challenges regarding this model. Consequently, they stated that adoption of CE would provide significant benefits, but an aggressive transition process may lead to big problems in terms of the unprepared system. Halonen et al. (2019) examined different circular economy approaches in the literature. Afterwards, by evaluating the suitability of these approaches in processes of transition to circular economy by firms with the purpose of strategic development, they provided synthesized guidelines to help firms in their decision-making processes. 
Parida et al. (2019) investigated the level of this benefit. They argued that this process would reach success and be possible by the participation of all members within the supply chain ecosystem, and the transition consisted of the preparation and transformation stages. Hao et al. (2020) reported that the anthropogenic material level used in wind energy brings about negativities regarding the environment. For the purpose of reducing this negative effect, they focused on how anthropogenic materials in the form of carbon fibers could be reused at the highest quality possible in a circular economy system. In the scope of the study, the economic outputs provided by the concept of circular economy were discussed over an application.

In their study on the plastic waste industry of Taiwan in the industrialization process, Wu et al. (2021) investigated how an industrial-level circular economy was structured by using an adaptive corporate governance framework and a network-based bricolage. Accordingly, they reported that developing nations could accumulate intrinsic social capacities, facilitate the emergence of network-based collective bricolages, a transition to green-related sectors may carry economic development even further, and new initiatives, firms and job opportunities could be created by establishing a circular economy. Mohan and Amit (2021) focused on recycling markets of vehicles that completed their lifespan, actors in these markets and the economic model formed by actors in these markets. In this context, official dismantler centers and unofficial dismantler centers involved in the recycling process of vehicle that completed lifespan were discussed. As a result of the study which examined the competition emerging in dismantling processes and the economic value brought by this competition, they proposed that healthier recycling in terms of the environment could be achieved if high-capacity vehicle manufacturers established dismantling units connected to themselves and management systems compatible with suitable policy instruments. Gautam et al. (2021) aimed to maximize resource productivity by establishing a supply chain network design based on circular economy to manage e-wasted caused by solar photovoltaic (PV) panels that completed their lifespan. For this, by using a prediction model projecting the waste amounts of solar PV panels that completed their lifespan and system balance, they aimed to reveal the size of the problem for India in particular, and they made managerial inferences by predicting the amounts of raw materials gained after recycling in the context of circular economy via the developed model.

Table 1 Methodologies and application areas of circular economy studies

\section{APPLICATION AREA}

\begin{tabular}{|c|c|c|c|c|c|c|c|}
\hline \multirow{2}{*}{ AUTHORS } & \multirow{2}{*}{ METHODOLOGY } & \\
\hline & & $\begin{array}{c}\text { POLICY } \\
\text { DEVELOPMENT }\end{array}$ & $\begin{array}{l}\text { GREEN } \\
\text { DESIGN }\end{array}$ & PRODUCTION & RECYCLING & ECONOMY & BUSINESS \\
\hline \multirow{3}{*}{$\begin{array}{l}\text { Moktadir et al. } \\
(2018)\end{array}$} & Graph Theory \& & & & & & & \\
\hline & Matrix & & $\checkmark$ & $\checkmark$ & & & \\
\hline & $\begin{array}{l}\text { Approach } \\
\text { Simulation }\end{array}$ & & & $d$ & & & \\
\hline (2019) & & & & & & & \\
\hline $\begin{array}{l}\text { Halonen et al. } \\
\text { (2019) }\end{array}$ & Literature Review & & & & & & $\checkmark$ \\
\hline $\begin{array}{l}\text { Parida et al. } \\
\text { (2019) }\end{array}$ & Data Analysis & & & $\checkmark$ & & & $\checkmark$ \\
\hline \multirow[t]{2}{*}{ Hao et al. (2020) } & Thermal & & & & & & \\
\hline & \& Char Analysis & & $\checkmark$ & & & $\checkmark$ & \\
\hline Wu et al. (2021) & Theoritical Model & & & & $\checkmark$ & & \\
\hline
\end{tabular}


Mohan and Amit Simulation Model

(2021)

Gautam et al. Optimization

(2021)

Model

\subsection{Literature Review on Open-Loop and Closed-Loop Supply Chain Studies}

This part of the literature has tackled the studies of the open-loop and closed-loop supply chain which enables to structure of the optimization model. Firstly, it is seen that open-loop recycling models in the literature have mainly focused on sustainability and green philosophy. The articles examined in the scope of the literature review were grouped based on the method used and the type of waste recycling focused on, and they are presented as a summary in Table 2. Some articles that will act as sources for the design of an open-loop recycling network to be integrated into the recycling process of PCB cards discussed in the scope of this study are examined below with their details.

Nicholson et al. (2009) argued that material selection decisions affect the product form, processing technology and supply chain configuration, and this situation has a large effect on the environmental performance of firms. For this reason, the authors investigated the recycling effects of products that have completed their lifespan, various analytical variations of relevant life cycle assessment (LCA) and the effects of these variations.

Nakamura et al. (2014) emphasized the importance of achieving sustainability in relation to problems such as potential material function losses that could be experienced in open-loop recycling or failure to meet quality requirements. Therefore, for the purpose of achieving sustainability and reducing losses, they developed a model based on dynamic material flow analysis. This way, they aimed to optimize the model by ensuring that the product could be monitored throughout its recycling, and potential losses and quality errors were taken into account.

Emphasizing the necessity of recycling for reducing the dimensions of the damage given to the environment originating from wastes, Liu and $\mathrm{Hu}$ (2017) focused on the concept of external economy in an open-loop supply chain. As a result of the study where comparative analyses were conducted by using the lifecycle assessment method, it was concluded that closed-loop supply chains and reverse supply chains are highly important in terms of solution of problems. 
Table 2 Methodologies and type of wastes of open-loop supply chain studies

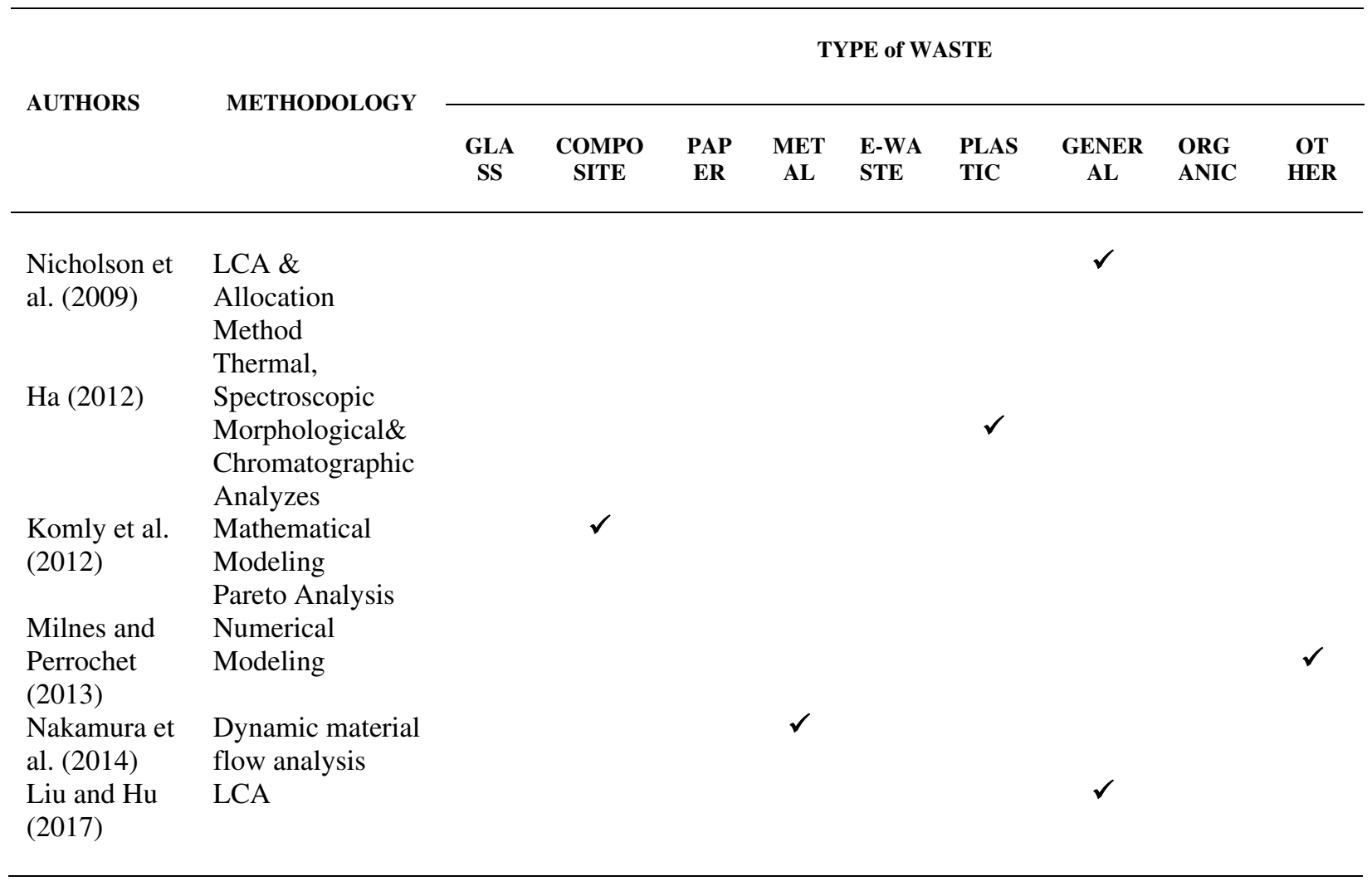

Secondly in this part, it is noticed that closed-loop models in the literature have mainly focused on recycling of WEEE and sustainable activities. Some articles that will role as sources for the design of a closed-loop recycling network to be integrated into the recycling process of PCB cards discussed in the scope of this study are examined below with their details.

Zlamparet et al. (2017) assessed the remanufacturing concept which can be embraced by the electronic manufacturing industry. The article uncovers values to decrease the amount of e-waste in the industry and academia in the scope of differential steps. They found that differences between developing and developed country's regions according to the concept of electronic waste remanufacturing. Fornasiero et al. (2016) evaluated the re-production networks to change the state-of-the-art processes in the case of WEEE which requires the configuration related to new manufacturing systems to improve the ability of a type of waste. They suggested a modular approach which is the EOL process for this configuration.Tseng et al. (2014) aimed to explore by using the analytical network process (ANP) analysis of green supply chain management (GSCM) under uncertainty for differences between close-loop and open network. This study analyzed to evaluate results for a real situation in interdependence among the proposed aspects and used criteria in GSCM. Cole et al. (2018) emphasized the e-waste becoming the fastest-growing waste stream due to technological advancement in the era. They signify that improvements in the efficiency of reverse logistics processes 
can increase reuse potential and efficient resource recycling. If availability and efficiency challenges can be dealt it will be possible to protect against value loss in global supply chains. Tan et al. (2020) emphasized that recycling methods for WPCBs manufacture high yields but leads to secondary pollution. They developed waste solutions in the PCB production that are minimize disadvantages with a win-win novel recycling method for WPCBs. Govindan et al. (2015) aim to review recently published papers in reverse logistic and closed-loop supply chain comphrensive search in scientific journals. They stressed closed-loop supply chain applications that have attracted attention academia and practitioners. They suggested future research opportunities for the closed-loop supply chain . Pishvaee et al. (2011) suggested a robust optimization model for tackling the doubtfulness of input data in a closed-loop supply chain network design problem. They to compared to evaluate the robustness of the solutions get by the novel robust optimization model and the deterministic mixed-integer linear programming model.

\subsection{Literature Review on Open-Loop and Closed-Loop Supply Chain Models that consider Circular Economy Perspective}

When articles where the concepts of "Open-Loop", "Closed-Loop," and "Circular Economy" were used together, were examined, it was found that there are very few studies in the literature on these. Therefore, we handled as a binary group of keywords which considered as "Open-Loop \& Circular Economy" and "Closed-Loop \& Circular Economy". It is seen that these studies, whose details are given in Table 3 have focused on other sectors rather than recycling electronic wastes.

Deschamps et al. (2018) proposed an open-loop-based circular economy approach for the real case problem of regaining mixed waste glasses accumulating in the garbage collection areas of the Quebec Government for the economy. In this context, two different production approaches were discussed, and the selected production processes were compared using the Monte-Carlo simulation method.

Kalverkamp (2018) stated that the circular economy had gained importance in terms of sustainability, and it contributes to the achievement of circularity even though some difficulties are experienced in supply chains as opposed to the case of reproduction. In this scope, the author used a qualitative research approach to investigate the effects of independent actors in the automotive supply chain on basic supply and how these apply supplier relations management for eliminating supply shortcomings in automotive reproduction. As a result of the study, it was revealed that operational costs should be reduced, and information sharing should be increased for open-loop supply chains to be able to compete with closed-loop supply chains.

Stating that supply chain research mainly focuses on closed loops, Kalverkamp and Young (2019) investigated the potential benefits of open-loops in the supply chain on the supply chain and their contributions to the weaknesses of the supply chain. With automotive recycling, three examples were selected and examined in the context of circular economy strategies. Afterwards, the effects of different alternative cycles on sustainability were analyzed. Finally, the 
authors emphasized the contribution of "open-loops" that make commercial innovation possible in supply chains and may improve sustainability outcomes in material supply chains.

Emphasizing that increasing the recycling of plastic wastes is an important priority in a circular economy, Huysveld et al. (2019) conducted an implementation showing that recycling mixed and contaminated plastic wastes without combustion is more beneficial for the environment. By analyzing recyclability benefit ratio and recycled content benefit ratio indicators with a product lifecycle perspective, they presented the potential environmental benefits of open-loop recycling.

Under the economic benefits of previous circular economy studies, Tseng et al. (2020) emphasized that resource utilization optimizes resource and environmental sustainability within the closed-loop system, especially by minimizing waste, emissions, energy leakage, and resource input. The authors examined the effects of a multi-level supply chain system on circular economy diffusion effects using the lifecycle assessment tool.

Sehnem et al. (2019) aimed to investigate overlaps, complements, and differences in circular economy models, within the scope of reverse logistics, closed-loop, industrial symbiosis, and industrial ecology. The authors identified areas in which it is often contradictory, requiring further research, unlike other literature surveys.

Brydges (2021) stressed a transition to a more sustainable and less wasteful fashion industry within the review of the circular economy framework which has a more efficient closed-loop economy. He searched and examined how to apply the circular economy principles in the Swedish fashion industry. After a detailed analysis, they identified the gaps between circular economy principles in fashion brand approaches.

Table 3 Studies where open-loop and closed-loop within the circular economy perspectives are discussed together

\begin{tabular}{|l|l|l|}
\hline AUTHORS & METHODOLOGY & AIM OF THE STUDY \\
\hline $\begin{array}{l}\text { Deschamps et } \\
\text { al. (2018) }\end{array}$ & $\begin{array}{l}\text { Life Cycle Impact Method } \\
\text { (Software, data analysis) \& } \\
\text { Monte Carlo Simulation }\end{array}$ & $\begin{array}{l}\text { To gain environmental values in open-loop recycling in a } \\
\text { circular economy with glass powder LCA in concrete }\end{array}$ \\
\hline $\begin{array}{l}\text { Huysveld et al. } \\
(2019)\end{array}$ & $\begin{array}{l}\text { Recyclability Benefit Rate \& } \\
\text { Recycled Content Benefit } \\
\text { Rate }\end{array}$ & $\begin{array}{l}\text { Development of circular economy utility indicators in } \\
\text { open-cycle mixed and contaminated plastic waste recycling }\end{array}$ \\
\hline $\begin{array}{l}\text { Kalverkamp } \\
(2018)\end{array}$ & Qualitative Research & $\begin{array}{l}\text { Investigate the influence of independent actors on core } \\
\text { supply and supply shortages in automotive remanufacturing. }\end{array}$ \\
\hline $\begin{array}{l}\text { Kalverkamp et } \\
\text { al. (2019) }\end{array}$ & $\begin{array}{l}\text { Mixed Method Research } \\
\text { Evaluate Three Cases }\end{array}$ & $\begin{array}{l}\text { Expands the environmental sustainability paradigm of } \\
\text { reverse supply chains in automotive remanufacturing. }\end{array}$ \\
\hline $\begin{array}{l}\text { Tseng et al. } \\
(2020)\end{array}$ & Life Cycle Assesment & $\begin{array}{l}\text { Examining the effects of a multi-level supply chain system } \\
\text { on the circular economy within the closed-loop system. }\end{array}$ \\
\hline $\begin{array}{l}\text { Sehnem et al. } \\
(2019)\end{array}$ & $\begin{array}{l}\text { A Systematic Literature } \\
\text { Review }\end{array}$ & $\begin{array}{l}\text { Investigating overlaps and differences in circular economy } \\
\text { models, within the scope of reverse logistics, closed-loop, } \\
\text { industrial symbiosis, and industrial ecology. }\end{array}$ \\
\hline Brydges (2021) & Interview & $\begin{array}{l}\text { Analyzing the circular economy framework which has a } \\
\text { more efficient closed-loop economy in the Swedish fashion } \\
\text { industry. }\end{array}$ \\
\hline
\end{tabular}


As far as the authors know, according to the comprehensive literature review that was conducted did not reveal any study on the open-loop and closed-loop supply chain network model based on circular economy regarding the recycling of electronic card wastes. In particular, it was seen that open-loop and closed-loop recycling products were associated with LCA in many studies. Likewise, it was determined that circular economy studies mostly intensified in the theoretical aspect, and there were fewer studies in the applied research aspect.

\section{METHODOLOGY}

The flowchart of the proposed methodology is demonstrated in Figure 3.
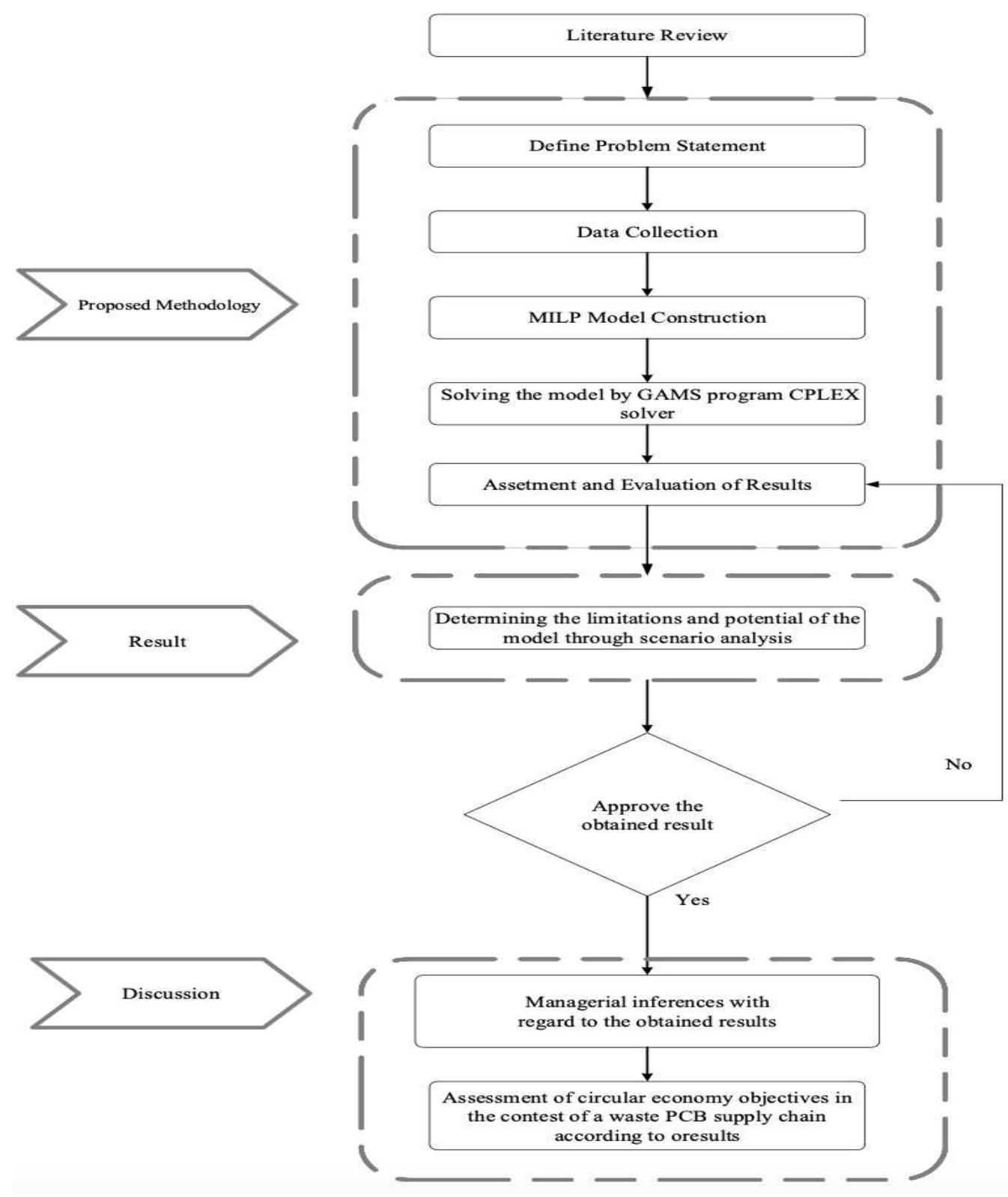

Figure 3 Flowchart of proposed metholodogy 


\section{1 Simultaneous Optimization of Closed-Loop and Open-Loop Networks with a Circular Economy Perspective}

As a result of a comprehensive literature review and interviews conducted with implementers, a model involving integrated closed-loop and open-loop supply chain network design regarding the lifecycle of PCBs was developed. The network design of the developed model is shown in Figure 4. In the model, the circular economy perspective represents value-adding processes such as repair, reuse, reproduction and recycling. The circular economy perspective discussed in this network design consists of a closed-loop supply chain involving a forward supply chain and a reverse supply chain together. The forward supply chain consists of four centers as suppliers, manufacturers, customers and users. The reverse supply chain consists of five centers as collection centers, disassembly centers, dismantler centers, recycling centers and waste. Moreover, the materials dismantled at the dismantler centers are sent to open-loop users to be sold in the internal market. According to the developed model, the flow in the network starts by purchasing four types of materials (A, B, C, D) from the suppliers to be used in PCB production by a certain amount of tons. The materials obtained from the suppliers are assembled at the manufacturing center, and printed circuit boards (PCB) are produced. The produced PCBs are sent to the customers who are producers of electrical and electronic equipment (EEE), and the customers used these PCBs to manufacture EEE. The produced EEE are sent to the users who are at the final point of the forward supply chain. These EEE that are used by the users turn into products whose lifespan has ended after a while. These products whose lifespan has ended are now named as waste electrical and electronic equipment (WEEE), and they are obtained from the users by disassembly centers as the first centers of the reverse supply chain. As the PCBs inside WEEE have deteriorated due to physical, chemical and environmental effects within their usage lifespan, they have now become WPCBs. At the disassembly center, after the WPCBs inside the WEEE are dismantled, they are sent to the collection center when they reach a certain capacity. The waste PCBs collected at the collection center are then sent to the dismantler centers. The waste PCBs are firstly sorted into four main parts at the dismantler center (Meng et al, 2018). $\omega$ percent is divided as material B, $\varphi$ percent is divided as material C, and $l l$ percent is divided as material D. These separated parts are sent to open-loop users to be sold in the internal market. After first dismantling, the $\mu$ percent material A which constitutes a significant part of the PCBs is turned into small pieces by grinding and crushing machines (This second-hand material is named as disassembled metalcore board). They are then sent to the recycling center where they are subjected to chemical processing to obtain the minerals in the structure of this metalcore board which constitutes the $t z$ percent of the WPCBs. After chemical procedure, what remains is waste with a $t$ percent ratio. The minerals such as gold, copper, silver and palladium that are obtained from the WPCBs at the recycling center are processed for reclamation, and these raw materials that are obtained are sent to the suppliers to be reused. 


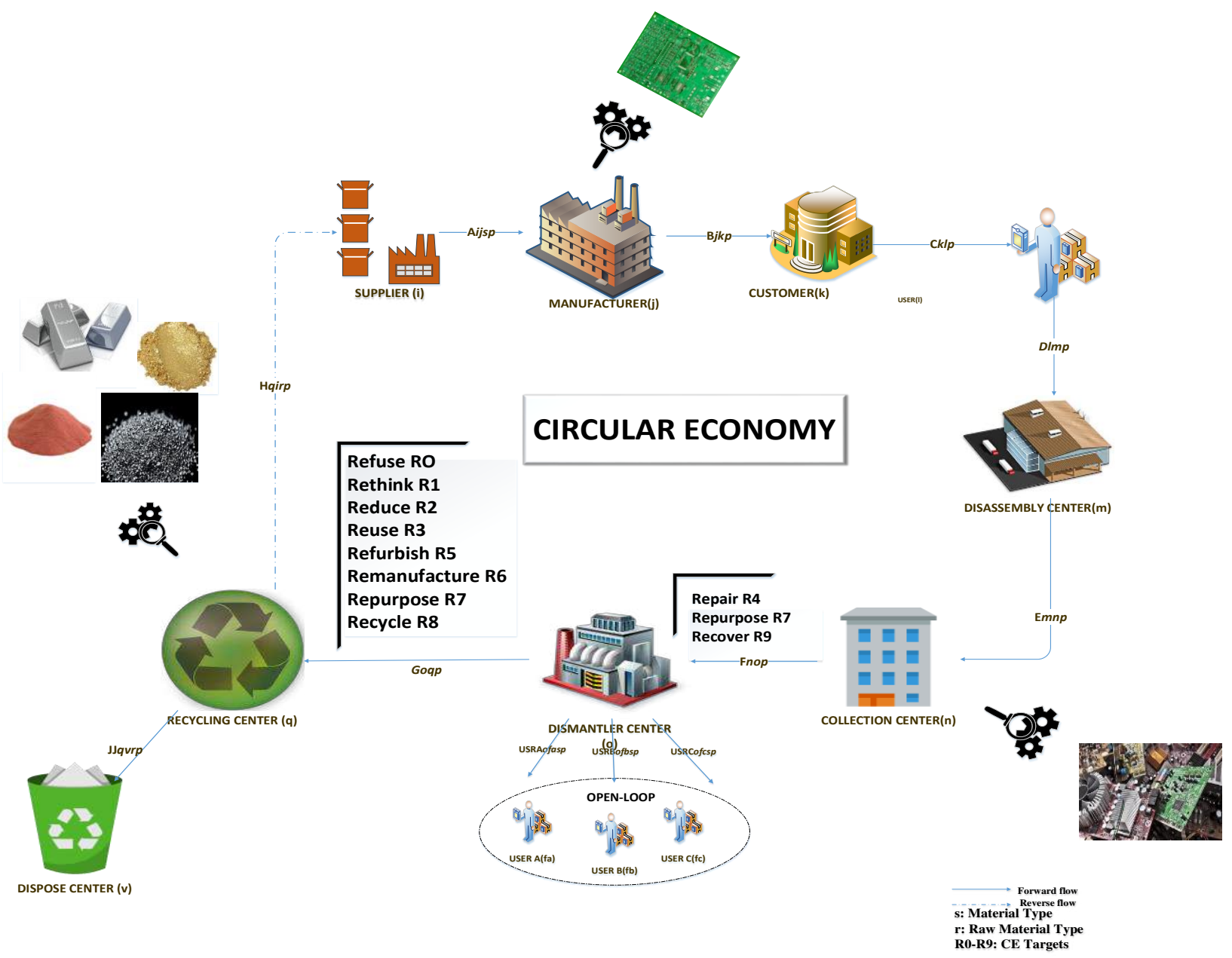

Figure 4 The Hybrid Closed-Loop and Open-Loop Network Design within the Circular Economy Perspective

During the solution of the model, an upper limit was determined regarding the numbers of manufacturing centers, disassembly centers, dismantler centers and recycling centers that needed to be opened for each period. This article aims to make optimum decisions regarding the capacity, the number of facilities, and their distances of the recycling, dismantler disassembly, collection centers for the most feasible solution. In the model shown in Figure 4, the decisionmaker (disassembly center) aims to maximize their net profit by minimizing their total transportation, purchasing and operation costs. Moreover, this article aims to make optimum decisions regarding the capacity, the number of facilities, and their distances of the recycling, dismantler disassembly, collection centers for the most feasible solution. Notations related to the model are presented in the Appendix section.Other assumptions regarding the model are given below.

- Customer demands are exactly and completely met for each period.

- The capacities of all facilities in the network are constant and exact.

- Transportation, purchasing, operation and fixed facility costs are constant and separate.

- The recycling rates are known beforehand.

- It is assumed that no waste is created during manufacturing of parts and from the disassembly center. 
- It is assumed that the raw materials obtained from the recycling center are not different to the original raw materials directly purchased by the supplier.

- It is assumed that the manufacturing centers are units that transform parts and raw materials into materials.

- The sum of the part percentages of the deliveries made from the dismantler center to different centers is assumed to be 1 . That is, $\mu+\omega+\varphi+l l=1$.

- It is assumed that the recycling center and disassembly center are controlled from a single center.

- The recycling rate and waste rate are assumed to be 1 . That is, $t t+t z=1$.

- It is assumed that the transportation costs do not vary based on the type or dimensions of the parts.

- It is assumed that the second-hand material constituting a large part of the PCB is not different to semifinished products.

- It is assumed that there is no carrying and sell-out cost.

\section{Explanation of Optimization Model}

The objective function belonging to the given MILP model consists of four parts (5.1). The first part (5.1 a) refers to the revenue obtained from the hybrid loop. The second part (5.1 b) refers to the operation costs for each facility, while the third part $(5.1 \mathrm{c})$ refers to the fixed facility establishment cost. The fourth part (5.1 d) represents the transportation costs. With the objective function, it is aimed to maximize the profit regarding the flow in the network.

\section{Objective Function}

$$
\begin{aligned}
& \operatorname{Maksz}\left(\sum_{q=1}^{Q} \sum_{i=1}^{I} \sum_{r=1}^{R} \sum_{p=1}^{P} H_{\text {qirp }} U_{\text {irp }}+\sum_{o=1}^{O} \sum_{\text {fa=1 }}^{F A} \sum_{s=1}^{S} \sum_{p=1}^{P} U S R A_{\text {ofasp }} d d_{\text {fasp }}\right. \\
& +\sum_{o=1}^{O} \sum_{f b=1}^{F B} \sum_{s=1}^{S} \sum_{p=1}^{P} S U P B_{o f b s p} e e_{f b s p} \\
& \left.+\sum_{o=1}^{O} \sum_{f c=1}^{F C} \sum_{s=1}^{S} \sum_{p=1}^{P} S U P C_{o f c s p} g g_{f c s p}-\sum_{j=1}^{J} \sum_{k=1}^{K} \sum_{p=1}^{P} B_{j k p} V_{k p}-\sum_{k=1}^{K} \sum_{l=1}^{L} \sum_{p=1}^{P} C_{k l p} W_{l p}\right) \\
& -\left(\sum_{i=1}^{I} \sum_{j=1}^{J} \sum_{s=1}^{S} \sum_{p=1}^{P} \alpha_{j p} A_{i j s p}+\sum_{l=1}^{L} \sum_{m=1}^{M} \sum_{p=1}^{P} \gamma_{m p} D_{l m p}+\sum_{m=1}^{M} \sum_{n=1}^{N} \sum_{p=1}^{P} \theta_{n p} E_{m n p}+\sum_{n=1}^{N} \sum_{o=1}^{O} \sum_{p=1}^{P} \beta_{o p} F_{n o p}\right. \\
& \left.+\sum_{o=1}^{O} \sum_{q=1}^{Q} \sum_{p=1}^{P} K_{q r p} G_{o q p}\right) \\
& -\left(\sum_{j=1}^{J} \sum_{p=1}^{P} f_{j p} X_{j p}+\sum_{m=1}^{M} \sum_{p=1}^{P} f_{m p} Y_{m p}+\sum_{n=1}^{N} \sum_{p=1}^{P} f_{n p} P P_{n p}+\sum_{o=1}^{O} \sum_{p=1}^{P} f_{o p} T_{o p}+\sum_{q=1}^{Q} \sum_{p=1}^{P} f_{q p} Z_{q p}\right)
\end{aligned}
$$




$$
\begin{aligned}
& -\left(\sum_{i=1}^{I} \sum_{j=1}^{J} \sum_{s=1}^{S} \sum_{p=1}^{P} A_{i j s p} \Delta_{i j}+\sum_{j=1}^{J} \sum_{k=1}^{K} \sum_{p=1}^{P} B_{j k p} \Delta_{j k}+\sum_{k=1}^{K} \sum_{l=1}^{L} \sum_{p=1}^{P} C_{k l p} \Delta_{k l}+\sum_{l=1}^{L} \sum_{m=1}^{M} \sum_{p=1}^{P} D_{l m p} \Delta_{l m}+\right. \\
& \sum_{m=1}^{M} \sum_{n=1}^{N} \sum_{p=1}^{P} E_{m n p} \Delta_{m n}+\sum_{n=1}^{N} \sum_{o=1}^{O} \sum_{p=1}^{P} F_{n o p} \Delta_{n o}+\sum_{o=1}^{O} \sum_{i=1}^{I} \sum_{s=1}^{S} \sum_{p=1}^{P} H_{q i s p} \Delta_{q i}+ \\
& \sum_{o=1}^{o} \sum_{f a=1}^{F A} \sum_{s=1}^{S} \sum_{p=1}^{P} S U P A_{o f a s p} \Delta_{o f a}+\sum_{o=1}^{O} \sum_{f b=1}^{F B} \sum_{s=1}^{S} \sum_{p=1}^{P} S U P A_{o f b s p} \Delta_{o f b}+ \\
& \left.\sum_{o=1}^{o} \sum_{f c=1}^{F C} \sum_{s=1}^{S} \sum_{p=1}^{P} S U P A_{o f c s p} \Delta_{o f c}\right) \mathrm{CC}
\end{aligned}
$$

The constraints (5.2) - (5.7) explain the capacity constraint regarding the relevant center. These constraints show that the quantity of product/material coming to the center cannot exceed the capacity of the relevant center. The constraint (5.2) shows that the quantity of the material carried from the supplier to the manufacturer cannot exceed the capacity of the relevant supplier.

$$
\sum_{j=1}^{J} A_{i j s p} \leq e_{i s p} \quad \forall i, s, p
$$

The constraint (5.3) shows that the quantity of the product carried from the manufacturer to the customers cannot exceed the capacity of the relevant manufacturer.

$$
\sum_{k=1}^{K} B_{j k p} \leq t_{j p} X_{j p} \quad \forall j, p
$$

The constraint (5.4) shows that the quantity of the product carried from the users to the disassembly center cannot exceed the capacity of the disassembly center.

$$
\sum_{l=1}^{L} D_{l m p} \leq d_{m p} Y_{m p}
$$$$
\forall m, p
$$

The constraint (5.5) shows that the quantity of the product carried from the disassembly center to the collection center cannot exceed the capacity of the collection center.

$\sum_{m=1}^{M} E_{m n p} \leq q_{n p} P P_{n p}$

$\forall n, p$

The constraint (5.6) shows that the quantity of the product carried from the collection center to the dismantler center cannot exceed the capacity of the dismantler center. 
$\sum_{n=1}^{N} F_{n o p}+\sum_{f a=1}^{F A} \sum_{s=1}^{S} U S R A_{o f a s p}+\sum_{f b=1}^{F B} \sum_{s=1}^{S} U S R B_{o f b}$

$\sum_{f c=1}^{F C} \sum_{s=1}^{S} U S R C_{o f c s p} \leq b_{o p} T_{o p}$

The constraint (5.7) shows that the total quantity of the material carried from the dismantler center to the recycling center and the material sent to the waste center cannot exceed the capacity of the recycling center.

$w r \sum_{o=1}^{o} G_{o q p}+\sum_{v=1}^{V} J J_{q v r p} \leq c_{q r p}$

$\forall q, r, p$

The constraints (5.8) - (5.9) guarantee that the customer and user demands are completely met for each period.

$\sum_{j=1}^{J} B_{j k p} \geq z_{k p}$

$\forall k, p$

$\sum_{k=1}^{K} C_{k l p} \geq n_{l p}$

$\forall l, p$

The constraints (5.10) to (5.14) show that the number of facilities belonging to the manufacturing, disassembly, collection and dismantler centers is constrained by an upper limit. In other words, they ensure that the number of facilities is under a desired level.

$$
\begin{aligned}
& \sum_{j=1}^{J} X_{j p} \leq L_{p} \\
& \sum_{m=1}^{M} Y_{m p} \leq N_{p} \\
& \sum_{n=1}^{N} P P_{n p} \leq R_{p} \\
& \sum_{o=1}^{o} T_{o p} \leq Z Z_{p} \\
& \sum_{q=1}^{Q} Z_{q p} \leq S_{p}
\end{aligned}
$$

The constraints (5.15) to (5.25) are the balance constraints. These constraints show that the quantity of the product or material entering the relevant facility is equal to the quantity of the product or material leaving the facility. 


$$
\begin{aligned}
& \sum_{i=1}^{I} \sum_{s=1}^{S} A_{i j s p}-w s \sum_{k=1}^{K} B_{j k p}=0 \\
& \forall j, p \\
& \forall k, p \\
& \sum_{j=1}^{J} B_{j k p}-\sum_{l=1}^{L} C_{k l p}=0 \\
& \sum_{k=1}^{K} C_{k l p}-\sum_{m=1}^{M} D_{l m(p+1)}=0 \\
& \sum_{l=1}^{L} D_{l m(p+1)}-\sum_{m=1}^{M} E_{m n(p+1)}=0 \\
& \sum_{m=1}^{M} E_{m n(p+1)}-\sum_{n=1}^{N} F_{n o(p+1)}=0 \\
& w r \sum_{n=1}^{N} F_{n o(p+1)} \mu-\sum_{q=1}^{Q} \sum_{r=1}^{R} G_{o q(p+1)}=0 \\
& \sum_{n=1}^{N} F_{n o(p+1)} \omega-\sum_{f a=1}^{F A} \sum_{s=1}^{S} U S R A_{o f a s(p+1)}=0 \\
& \sum_{n=1}^{N} F_{n o(p+1)} \varphi-\sum_{f b=1}^{F B} \sum_{s=1}^{S} U S R B_{o f b s(p+1)}=0 \\
& \sum_{n=1}^{N} F_{n o(p+1)} l l-\sum_{f c=1}^{F C} \sum_{s=1}^{S} U S R C_{o f c s(p+1)}=0 \\
& w r \sum_{o=1}^{o} G_{o q(p+1)} t t-\sum_{v=1}^{V} J J_{q v r(p+1)}=0 \\
& w r \sum_{o=1}^{o} G_{o q(p+1)} t z-\sum_{i=1}^{I} H_{q i r(p+1)}=0 \\
& \forall l, p \\
& \forall n, p \\
& \forall o, p \\
& \forall o, p \\
& \forall o, p \\
& \forall o, p \\
& \forall o, p \\
& \forall q, r, p \\
& \forall q, r, p
\end{aligned}
$$

The constraint (5.26) refers to the non-negative values of the decision variables.

$A_{i j s p}, B_{j k p}, C_{k l p}, D_{l m p} E_{m n p}, F_{n o p}, G_{o q p}, H_{q i r p}, J J_{q v r p}, \mathrm{USRA}_{o f a s p}, \mathrm{USRB}_{\text {ofbsp }}$, $\mathrm{USRC}_{\text {of csp }} \geq 0$

The constraint (5.27) refers to the binary variables that can take a value of 0 or 1 .

$X_{j p}, Y_{m p}, P P_{n p}, T_{o p}, Z_{q p} \in\{0,1\}$ 


\subsection{Description of Data}

The model consists of 4 suppliers, 2 manufacturers, 3 customers, 5 users and 3 different open-loop users. Additionally, there are 2 disassembly centers, 2 collection centers, 2 dismantler centers and 2 recycling centers in the model. In the model, 4 types of parts and 4 types of raw materials are defined. Table 4 shows the values of the parameters of the model. The parameter values were randomly specified in a determined interval. The model was designed to consider flows that occur for 3 periods. In this model, the unit transportation cost is defined as $0.5 \mathrm{TL}$ per ton $/ \mathrm{km}$. The unit purchasing, processing and fixed facility costs vary periodically. The manufacturing, disassembly, collection, dismantler and recycling centers are restricted to three centers at most for each. From the dismantler center, the ratio of the B materials sent to user A is: $0.25(\omega)$; the ratio of the C materials sent to user B is: $15(\varphi)$, and the ratio of the D materials sent to user C is: $0.05(l l)$. A $45 \%$ part of the recycled product is sold to be reused in the internal market, and this way, profit is provided for the loop. On the other hand, the remaining $55 \%(\mu)$, material $\mathrm{A}$, is sent to the recycling center to be processed. $70 \%(t z)$ of it is separated into raw materials such as silver, gold, copper and palladium with chemical analysis methods based on the percentage amounts it contains (Yao 2020). After the chemical processes, $30 \%(t t)$ waste is created. The ratios of the components found in WPCBs are as 64\% copper, $20 \%$ silver, $12 \%$ gold and

$4 \%$ palladium (Ning et al. 2017). By sending the raw materials dismantled based on these ratios to the suppliers to be reused in the network, a contribution is made to the circular economy.

Table 4 Values of Random Generated Parameters

\begin{tabular}{ll}
\hline Parameters & Interval \\
\hline Distance between supplier and manufacturer $(\mathrm{km})$ & $100-250$ \\
Distance between manufacturer and customer $(\mathrm{km})$ & $100-150$ \\
Distance between customer and user $(\mathrm{km})$ & $100-220$ \\
Distance between user and disassembly center $(\mathrm{km})$ & $100-200$ \\
Distance between disassembly center and collection center $(\mathrm{km})$ & $100-150$ \\
Distance between collection center and dismantler center $(\mathrm{km})$ & $100-200$ \\
Distance between dismantler center and userA $(\mathrm{km})$ & $10-90$ \\
Distance between dismantler center and userB $(\mathrm{km})$ & $10-90$ \\
Distance between dismantler center and userC $(\mathrm{km})$ & $10-90$ \\
Distance between recycling center and supplier $(\mathrm{km})$ & $250-300$ \\
Capacity of supplier (ton) & $5000-6000$ \\
Capacity of manufacturer (ton) & $5000-6000$ \\
Capacity of disassembly center (ton) & $5000-6000$ \\
Capacity of collection center (ton) & $5000-6000$
\end{tabular}


Capacity of dismantler center (ton)

5000-6000

Capacity of recycling center (ton)

5000-6000

Capacity of user A (ton)

$5000-6000$

Capacity of user B (ton)

5000-6000

Capacity of user C (ton)

5000-6000

Demand of customer (ton)

1000-2000

Demand of user (ton)

1000-2000

Largest number of manufacturer

3

Largest number of disassembly center

3

Largest number of collection center

3

Largest number of dismantler center

Largest number of recycling center

3

The strengths and weaknesses of the model designed are compared in Table 5.

Table 5. Strengths and Weaknesses of the Model

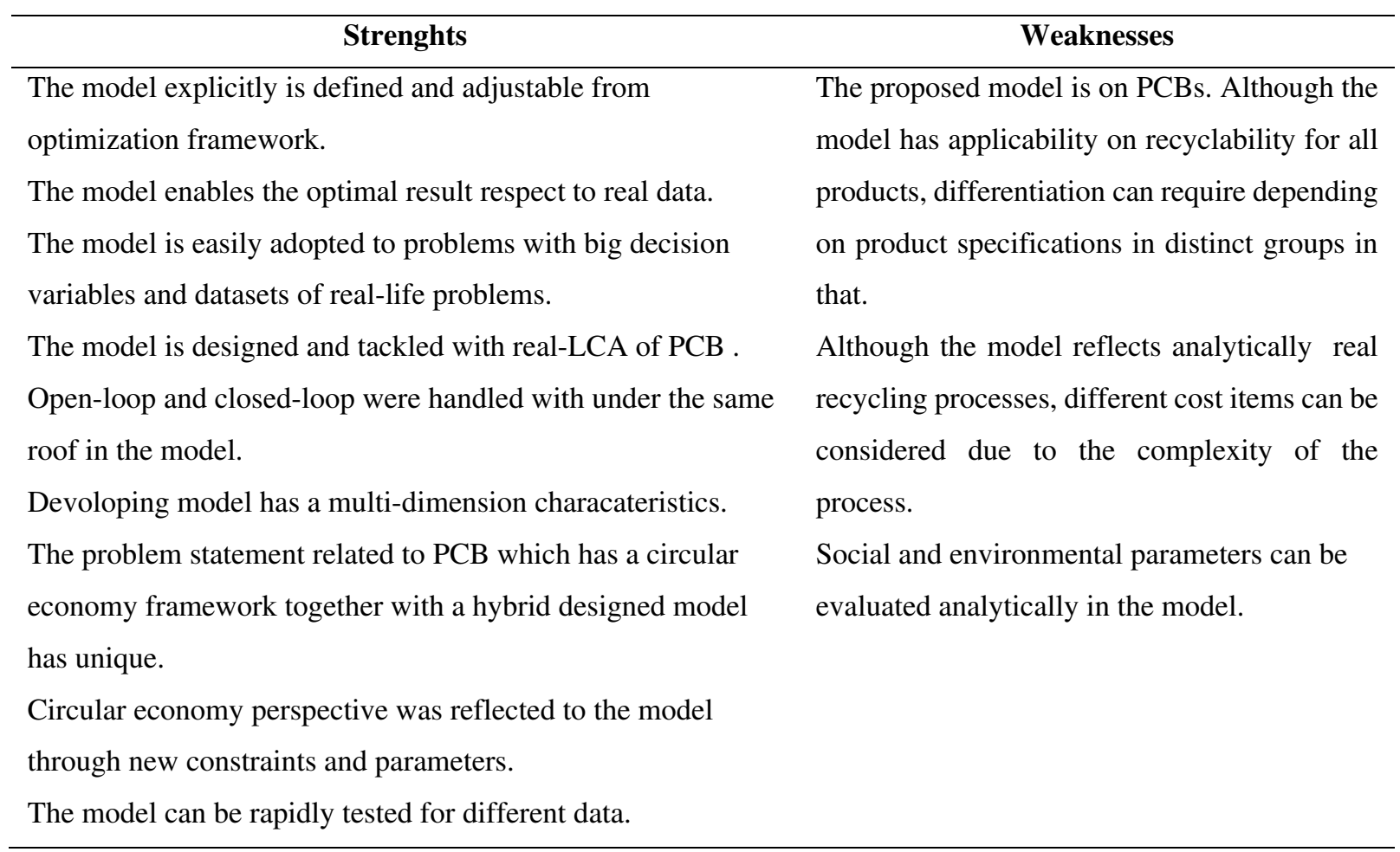




\section{RESULTS}

\subsection{Computational Results}

The mixed-integer linear programming (MILP) model was solved in 0,109 seconds with the GAMS program CPLEX solver on the computer with a 1,4 GHz processor and 4GB of RAM. The objective function is implemented on a hybrid network model design that is aimed to maximize profit within the framework of the circular economy. The objective function value that maximizes profit in network design is 9,712,360,457 TL. Table 6 illustrates data and percentages of each performance indicator in the objective function. According to the results, the most important factors affecting profitability are in-cycle acquisition revenues. Transportation cost is negligible compared to other costs. Therefore, when directing investments, businesses can also ignore transportation costs compared to other costs. Recycle and remanufacturer applications are also comprehending from the results that provide high profitability for businesses in circular economy-based approaches. Figure 4 and Figure 5 illustrate overall material flow, quantities, and types of the developed model related to periods.

Table 6 Performance indicator values of the objective function

\begin{tabular}{lll}
\hline & Performance Indicators of Objective Function & Value (TL) \\
\hline OF & The objective function value (Net Profit) & $9,712,360,457$ \\
PI1 & Total revenue & $15,256,821,148$ \\
PI2 & The total cost of operation & $5,533,357,058$ \\
PI3 & The total cost of fixed facility & $1,574,920$ \\
PI4 & The total cost of transportation & $9,528,712$ \\
\hline
\end{tabular}

According to Figure 5, the first period the flow starts with 1151,220; 1973,520; 767,480; 1589,780-tons material purchase form Supplier1 and 520,814; 892,825; 347,210; 719,220-tons material purchase from Supplier3. PCBs that are produced with these materials by manufacturers are transmitted to customers and users respectively. The firstperiod flow is completed in users.

In the second period, the flow starts with the supply of material from outside. Furthermore, this flow is continued to the manufacturer, customer and users, respectively. However, in this period, users from the first period, 1000; 1700; 2062,$06 ; 852 ; 548 ; 1800$-tons of the PCBs are transferred to the disassembly center. 5352; 480; 2130,06 tons of Waste PCBs removed from disassembled products are sent to the collection center. 3877,931; 1954,069; 2130,06-tons of Waste PCBs are sent from the collection center to the dismantler center. Materials removed from the Waste PCBs from the dismantler center are sold to open-loop users. Of the sold materials, 1990,517-tons of iron shipped to User A, 1194,311 tons of plastic shipped to User B, and 398,104 tons of iron shipped to User C. Furthermore, 2132,862; 2246,276-tons of waste metal core boards are sent to the recycling center. After chemical processes in the recycling center, the metal core board decomposes to its raw materials at certain rates. After the separation process 131,374; 262,$748 ; 394,122 ; 525,497$ tons of the waste occurred from raw material. During this period, 122,616 tons of palladium, 1961,854 tons of copper, 367,848 tons of gold and 613,079 tons of silver are obtained with chemical 
operations. Finally, these raw materials are sent to the material suppliers for the production/consumption in the loop. Thus, the cycle is to get some of its raw material needs from recycling.

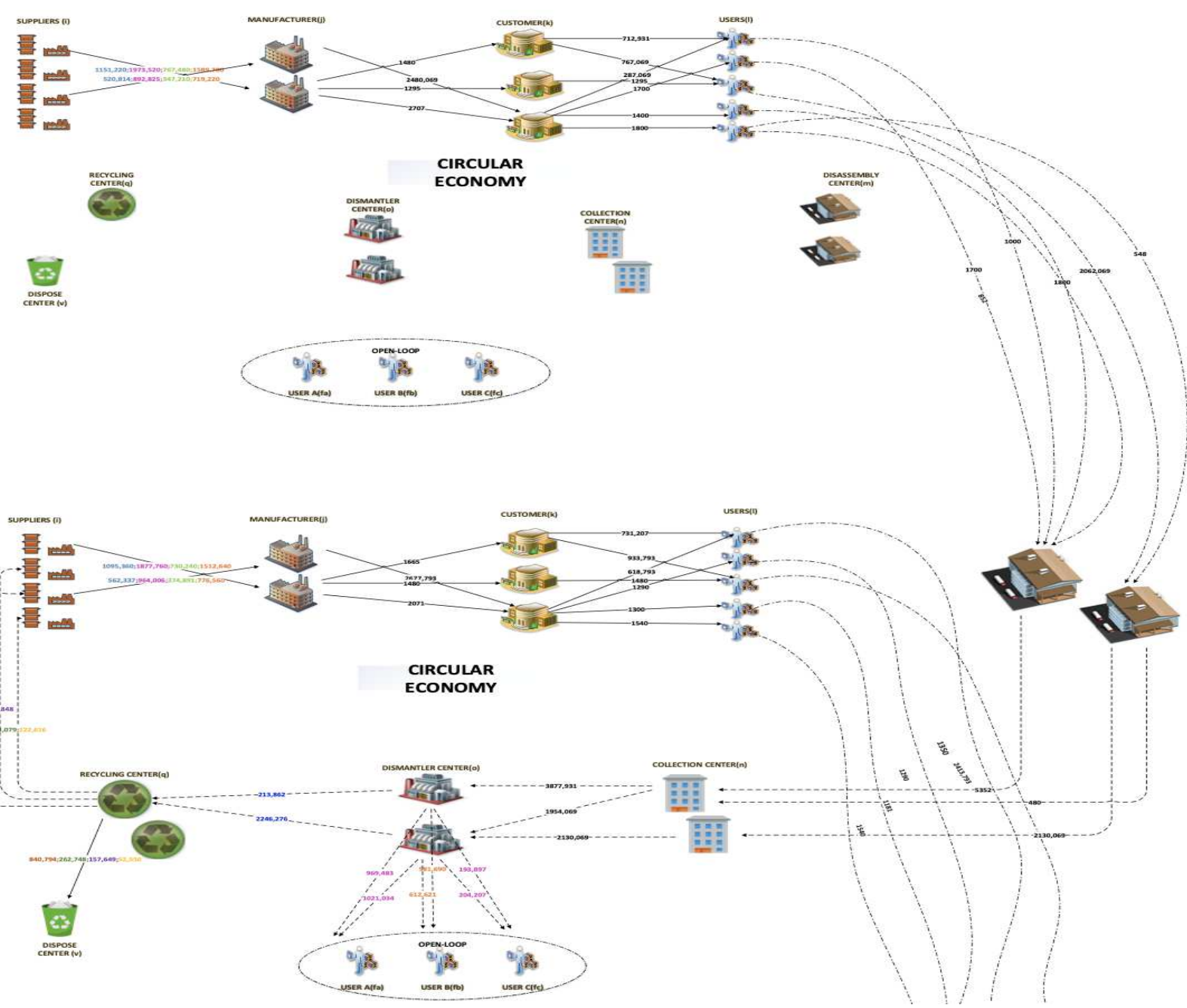

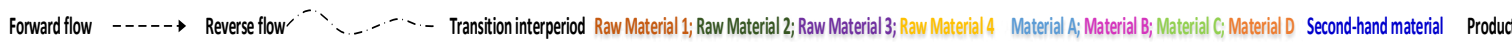

Figure 5 The best distribution network related to first and second periods

In the third period, the flow begins with the supply of material from outside. Furthermore, this flow is continued to the manufacturer, customer and users respectively. Figure 6 shows that the next period will be transferred to the disassembly center and the cycle will continue in this way. In the third period, products from users in the second period are transferred to the disassembly center and are began their journey through the supply chain respectively. In this period, the type of materials sent from the dismantler center to open-loop users differ from the second period. Materials removed from the scrap PCBs from the separation center are sold to open-loop users. Of the sold materials, 1973,448 tons of iron sent to User A, 1194,311 tons of aliminum sent to User B, and 394,689 tons of iron sent to User C. The 
rest is broken down into raw materials and sent to suppliers. Waste metal core boards are sent to the recycling center to chemical analysis and are separated into the raw materials (Yamane et al. 2011). Finally, these raw materials are sent to material suppliers for the production/consumption in the loop. Therefore, recycling in the network is completed simultaneously the open-loop and closed-loop design and within the circular economy perspective.

From this viewpoint with the computational case study demonstrated that the network design contribution profit that consists of mai nly based on economic dimensions in addition to environmental and social impact.

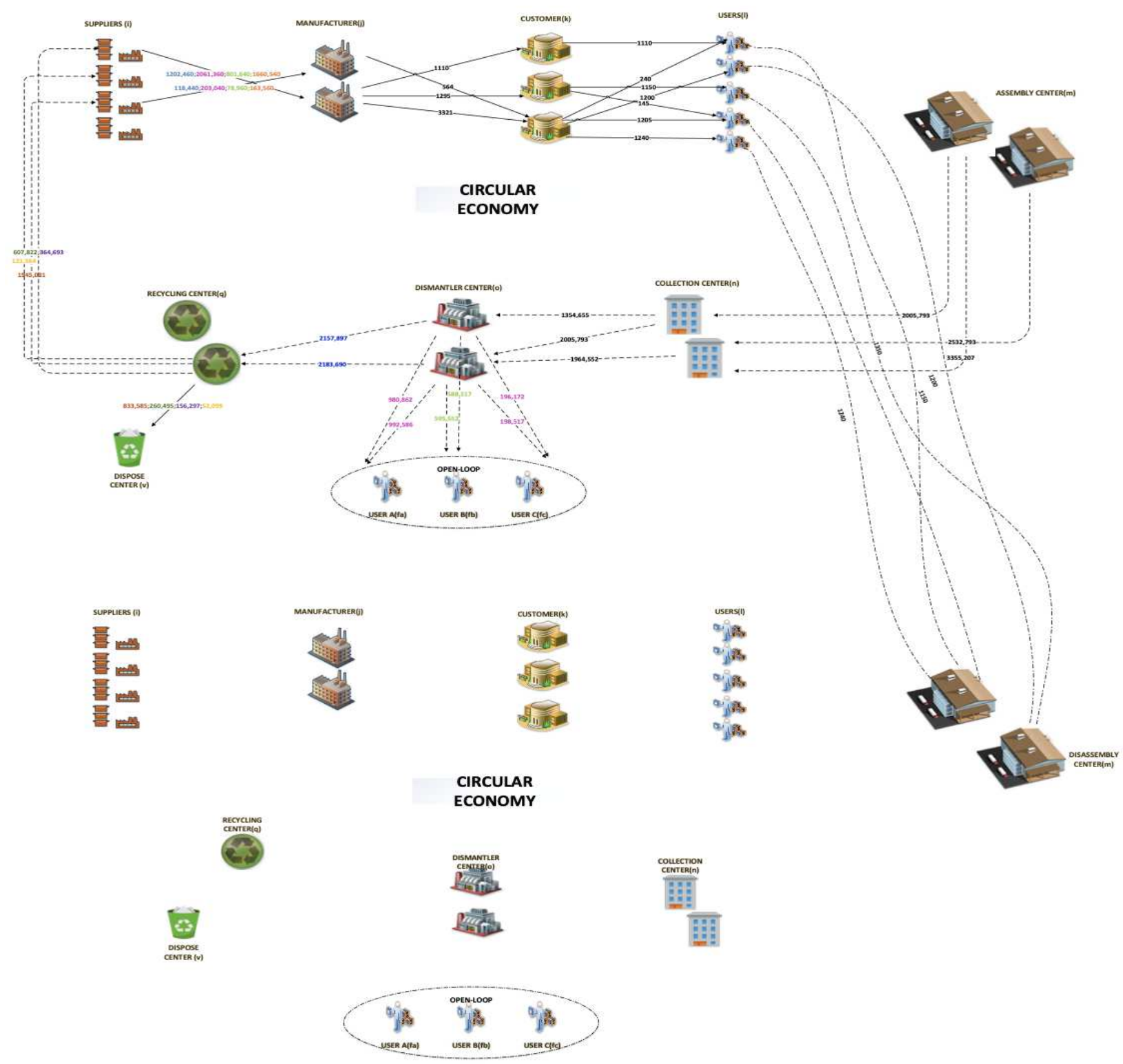

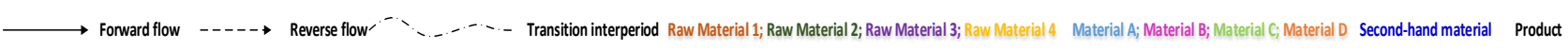

Figure 6 The best distribution network related to third and next periods 


\subsection{Scenario Analyses}

Scenario analyses are provided to see the limits and potential of the model. Each scenario is based on the initial optimal model. The boundary of the model and the situations in which the performance indicators that constitute the objective function that may be affected are taken in comprehensively by scenario analysis. These are examined in terms of sensitivities on objective function as in the optimization study of supply chain network design by Özceylan et al. (2014). PI1, PI2, PI3 and PI4 have represented respectively the total revenue, total operation cost, total fixed facility cost and total transportation cost. In this article, numerical examples are presented showing cost savings that can be achieved by solving with scenario analysis.

\subsubsection{Sensitivity to changes in capacities of facilities (Scenario 1)}

Based on the assumption that the capacities of these facilities are within normal limits, the manufacturer capacities are initially reduced by $5 \%$. Then the capacity values are systematically reduced and continued until the infeasible solution is given.

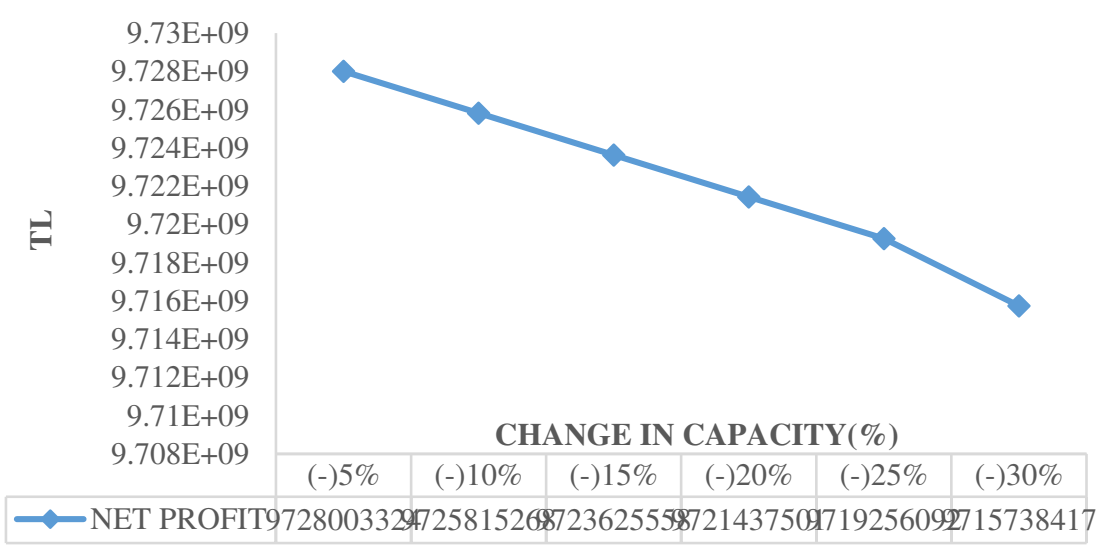

Figure 7 Results of net profit related to Scenario 1a

Along with the reduction of manufacturer capacity, a decrease in net profit is observed. Because of the requirement for new facilities to meet the product flow, fixed facility cost and transportation costs have also increased. A noticeable decrease in profit is observed as costs increase. The results are shown graphically in Figure 7 and Figure 8. 


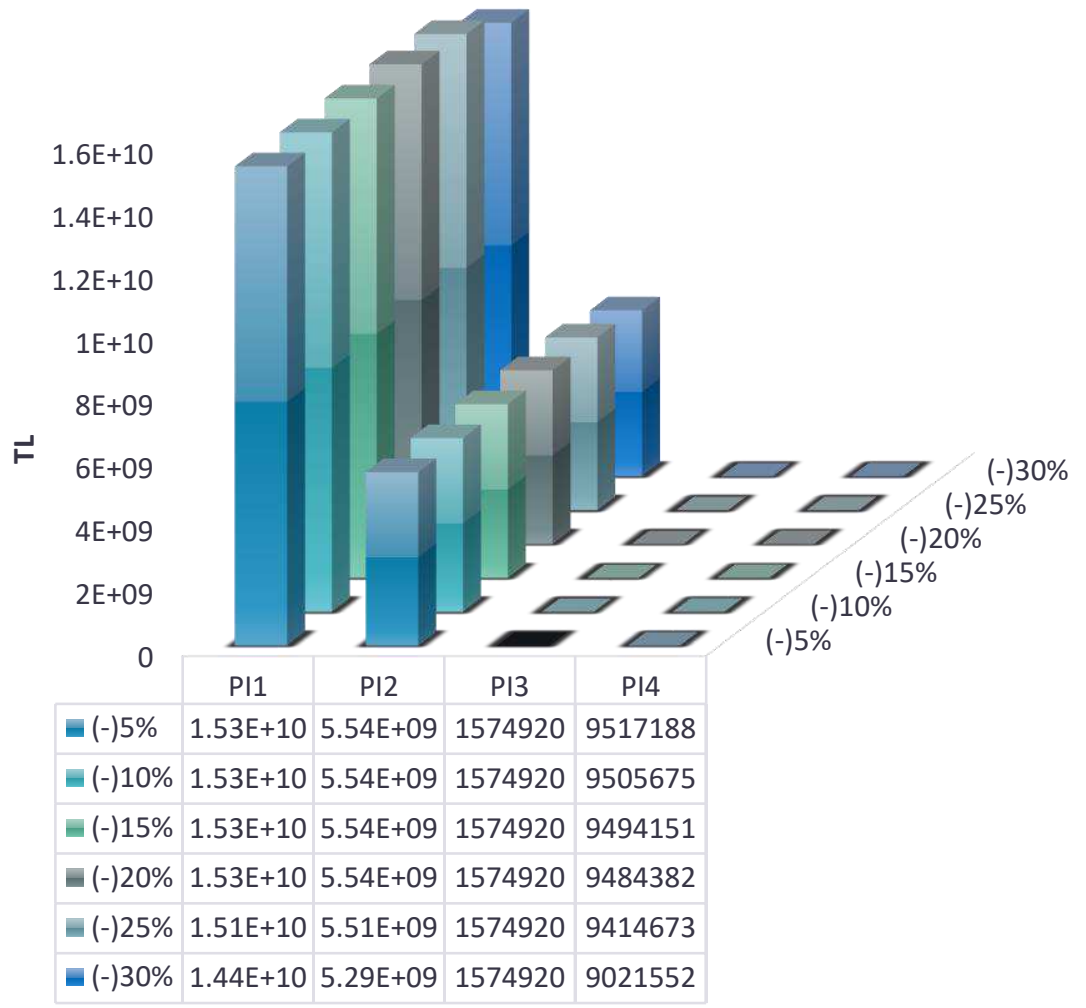

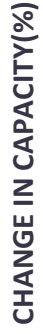

Figure 8 Results of performance indicators in objective function related to Scenario 1a

According to Scenario 1b, the capacity of the collection center is augmented from $10 \%$ to $90 \%$. The results are shown graphically in Figure 9 and Figure 10.

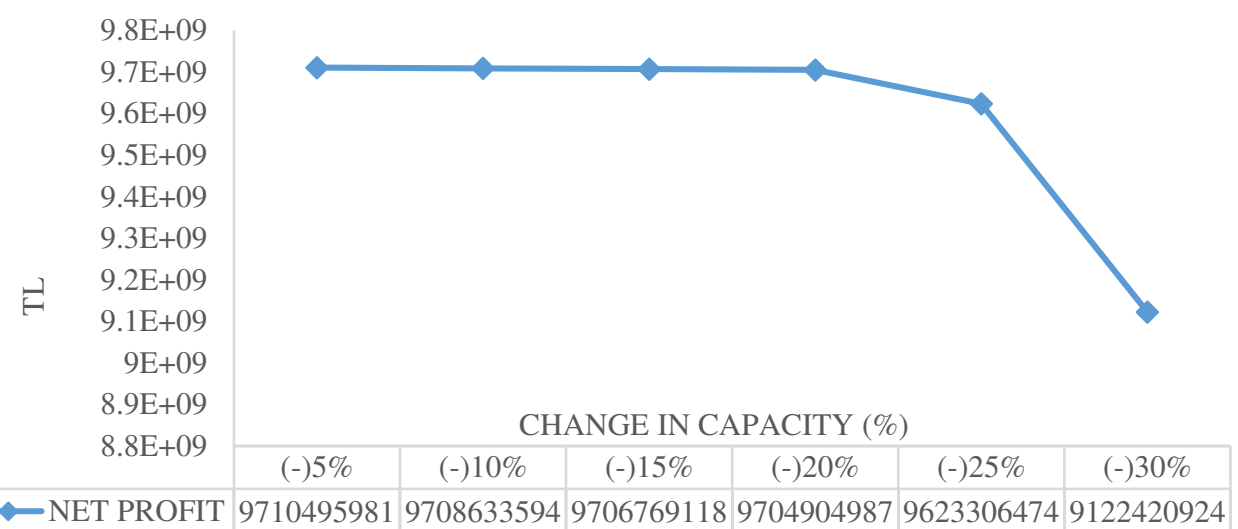

Figure 9 Results of the net profit related to Scenario $1 b$ 
As collection center capacity is augmented, fixed facility costs and transportation costs are reduced simultaneously. There has been an increase in operating costs as the flow of product/material purchased per center is increased. Because of this flow, the revenue of sales has risen in net profit. In particular, there have been serious rises in profits after a more than 70 percent increase in capacity.

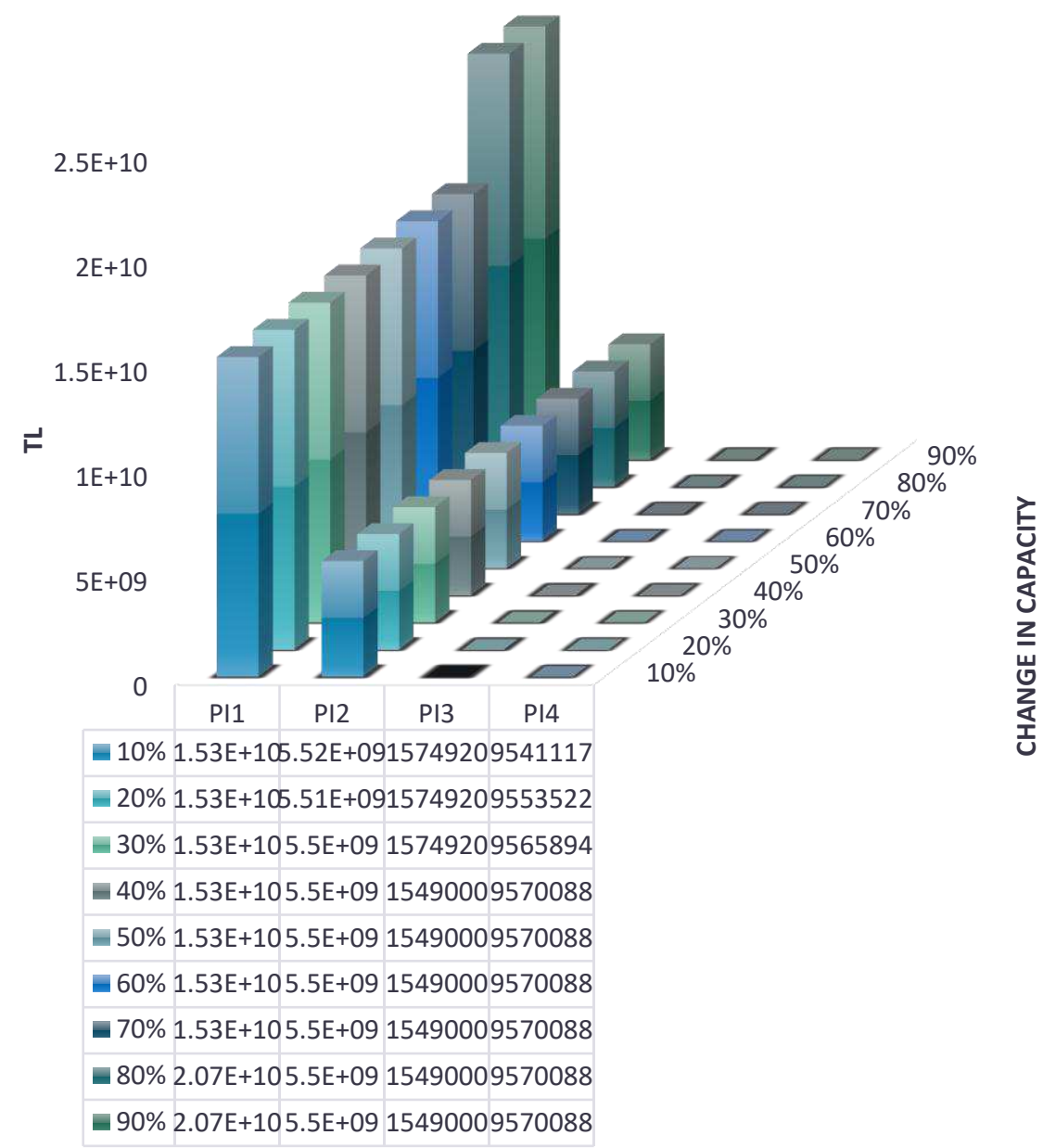

Figure 10 Results of performance indicators in objective function related to Scenario $1 \mathrm{~b}$

As a consequence of the different changes of capacity;

- Operation and transportation costs are increased due to the reducing capacity of the centers that lead to the requirement of a new plant.

- It is observed that net profit decreases as revenue-generating purchasing costs decrease for the cycle.

- Since reducing capacity is entailed raising total cost, keeping capacity at a high rate will increase profitability over the total cost. 


\subsubsection{Sensitivity to changes in customers' demands (Scenario 2)}

The change in demand has affected transportation costs and in-cycle purchasing costs, which has to depend on the product flow. Since capacities have conformed to the ascendant demand, extra fixed facility costs have not occurred. User demands have balanced customer demands. As a result, increased product demand by customers has been met to a certain level. The results are presented in Table 7 and graphically showed Figure 11.

Table 7 Results according to Scenario 2

\begin{tabular}{cccccc}
\hline $\begin{array}{c}\text { CHANGE IN } \\
\text { DEMAND }\end{array}$ & NET PROFIT & PI1 & PI2 & PI3 & PI4 \\
\hline$(+) 10 \%$ & $2,063 \mathrm{E}+10$ & $5,533 \mathrm{E}+09$ & $1,575 \mathrm{E}+06$ & $9,707 \mathrm{E}+06$ & $2,063 \mathrm{E}+10$ \\
$(+) 20 \%$ & $2,062 \mathrm{E}+10$ & $5,533 \mathrm{E}+09$ & $1,575 \mathrm{E}+06$ & $9,694 \mathrm{E}+06$ & $2,062 \mathrm{E}+10$ \\
$(+) 30 \%$ & $2,061 \mathrm{E}+10$ & $5,533 \mathrm{E}+09$ & $1,575 \mathrm{E}+06$ & $9,686 \mathrm{E}+06$ & $2,061 \mathrm{E}+10$ \\
$(+) 40 \%$ & $2,061 \mathrm{E}+10$ & $5,533 \mathrm{E}+09$ & $1,575 \mathrm{E}+06$ & $9,679 \mathrm{E}+06$ & $2,061 \mathrm{E}+10$ \\
$(+) 50 \%$ & $2,060 \mathrm{E}+10$ & $5,533 \mathrm{E}+09$ & $1,575 \mathrm{E}+06$ & $9,671 \mathrm{E}+06$ & $2,060 \mathrm{E}+10$ \\
$(+) 60 \%$ & $2,059 \mathrm{E}+10$ & $5,533 \mathrm{E}+09$ & $1,575 \mathrm{E}+06$ & $9,664 \mathrm{E}+06$ & $2,059 \mathrm{E}+10$ \\
\hline
\end{tabular}

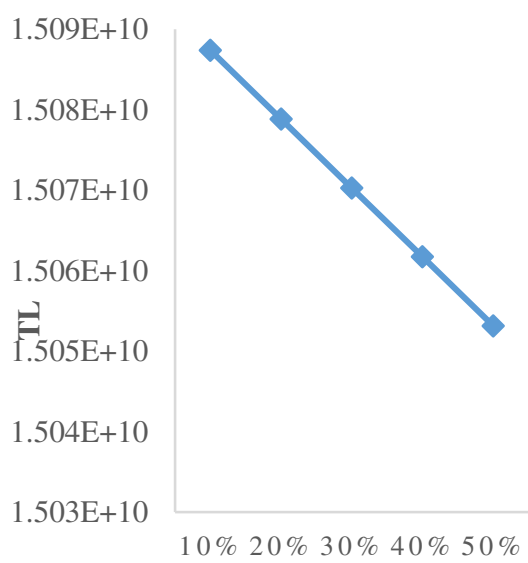

CHANGE IN DEMAND(\%) $\leadsto$ NET PROFIT

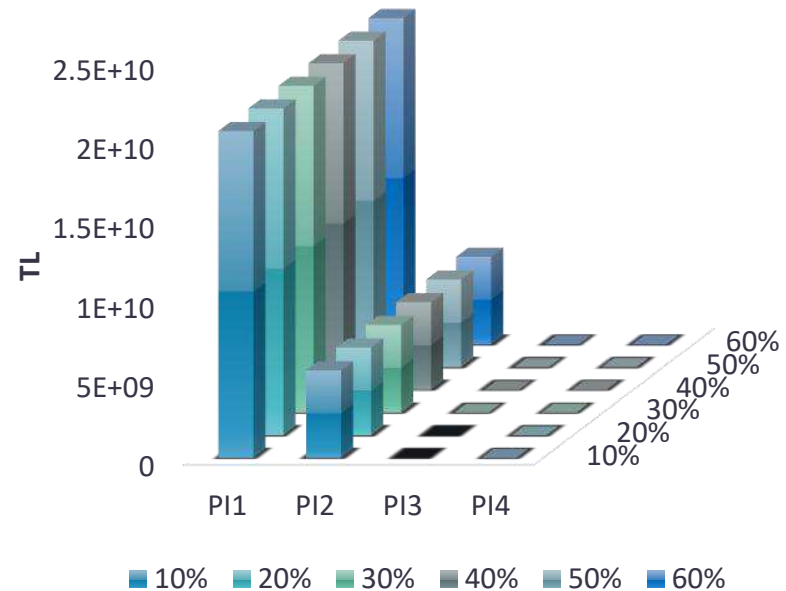

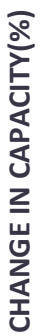

Figure 11 Results according to Scenario 2

\subsubsection{Sensitivity to changes in manufacturer capacity and transportation cost (Scenario 3)}

In this scenario, the raise of the manufacturer's capacity starting from 15 percent and the exponential increase in transportation costs are assumed. For this purpose, the change in performance indicators in the objective function values are examined. As the capacity increases, this facility can meet the requirement more flexibly. Even if transportation costs increase, the reduction of the fixed facility and operating costs show an increase in net profit. At 
the last change, high transport costs caused an unbalanced slope by fall in profits. The results are presented in Table 8 and graphically showed Figure 12

Table 8 Results according to Scenario 3

\begin{tabular}{cccccccc}
\hline NC & $\begin{array}{c}\text { CHANGE IN } \\
\text { CAPACITY }\end{array}$ & $\begin{array}{c}\text { CHANGE IN } \\
\text { UNIT } \\
\text { TRANSPOR } \\
\text { TATION } \\
\text { COST }\end{array}$ & NET PROFIT & PI1 & P12 & P13 & PI4 \\
\hline C1 & $15 \%$ & $3 \%$ & $9,721 \mathrm{E}+09$ & $1,526 \mathrm{E}+10$ & $5,524 \mathrm{E}+09$ & $1,40 \mathrm{E}+06$ & $9,897 \mathrm{E}+06$ \\
C2 & $30 \%$ & $7 \%$ & $9,727 \mathrm{E}+09$ & $1,526 \mathrm{E}+10$ & $5,518 \mathrm{E}+09$ & $1,40 \mathrm{E}+06$ & $1,027 \mathrm{E}+07$ \\
C3 & $45 \%$ & $12 \%$ & $9,733 \mathrm{E}+09$ & $1,526 \mathrm{E}+10$ & $5,511 \mathrm{E}+09$ & $1,40 \mathrm{E}+06$ & $1,064 \mathrm{E}+07$ \\
C4 & $60 \%$ & $16 \%$ & $9,736 \mathrm{E}+09$ & $1,526 \mathrm{E}+10$ & $5,509 \mathrm{E}+09$ & $1,04 \mathrm{E}+06$ & $1,102 \mathrm{E}+07$ \\
C5 & $75 \%$ & $23 \%$ & $9,735 \mathrm{E}+09$ & $1,526 \mathrm{E}+10$ & $5,509 \mathrm{E}+09$ & $1,04 \mathrm{E}+06$ & $1,178 \mathrm{E}+07$ \\
C6 & $90 \%$ & $30 \%$ & $9,734 \mathrm{E}+09$ & $1,526 \mathrm{E}+10$ & $5,509 \mathrm{E}+09$ & $1,04 \mathrm{E}+06$ & $1,235 \mathrm{E}+07$ \\
\hline
\end{tabular}

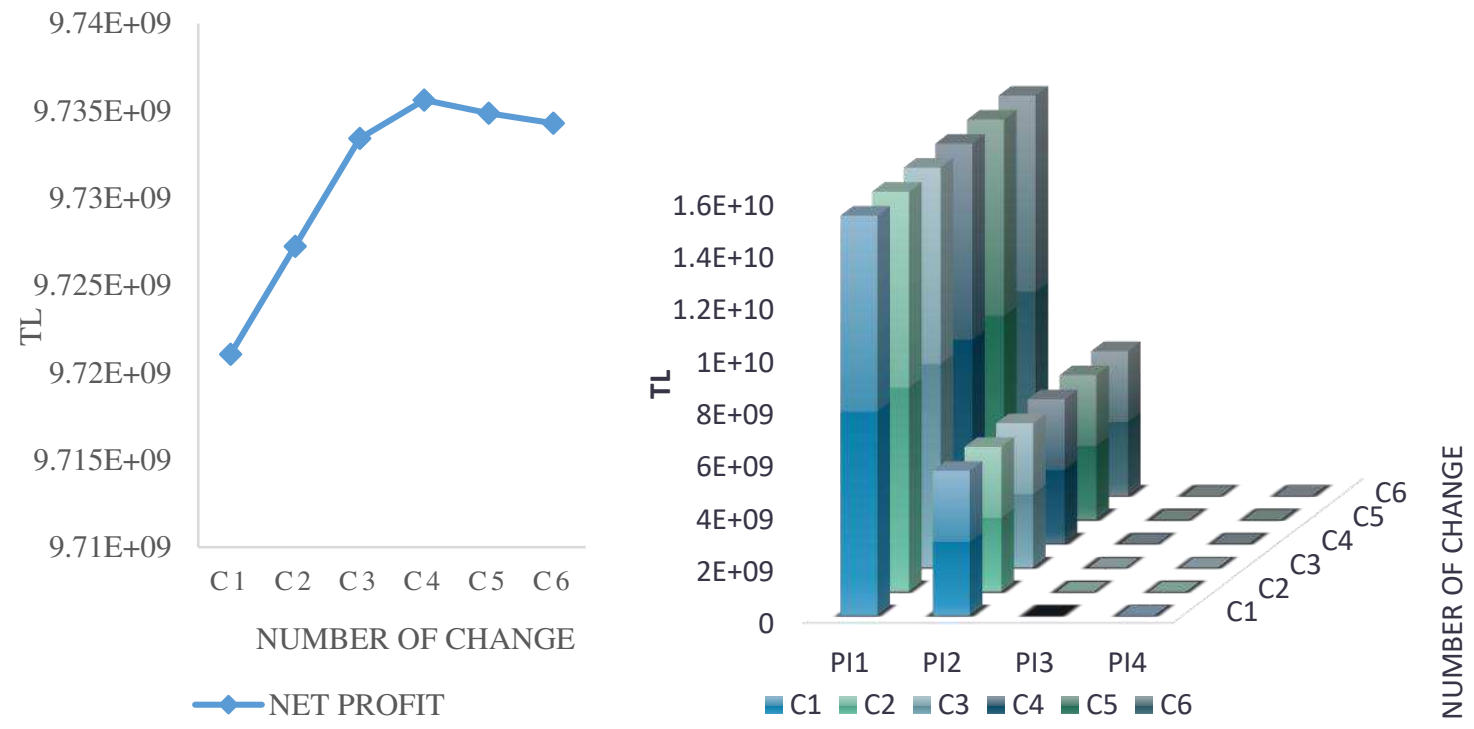

Figure 12 Results according to Scenario 3

\subsubsection{Sensitivity to changes in the recycling ratio (Scenario 4)}

In this scenario, the effect of the change in the recycling ratio on the objective function is examined. As the amount of waste sent to the recycling center decreases, there are exalted increases in net profit. In this scope, recycling centers should have advanced technological machinery and equipment. With ionic methods that have high separation potential, they can get more recycled raw materials in a framework that has higher profit and environmental returns. The results are shown in Table 9 and graphically Figure 13. 
Table 9 Results according to Scenario 4

\begin{tabular}{crrcccc}
\hline $\begin{array}{c}\text { NUMBER OF } \\
\text { CHANGE }\end{array}$ & $\boldsymbol{T} \boldsymbol{t}$ & tz & \multicolumn{1}{c}{ PI1 } & PI2 & PI3 & PI4 \\
\hline C1 & $25 \%$ & $75 \%$ & $1,526 \mathrm{E}+10$ & $5,509 \mathrm{E}+09$ & $1,041 \mathrm{E}+06$ & $1,235 \mathrm{E}+07$ \\
C2 & $20 \%$ & $80 \%$ & $1,741 \mathrm{E}+10$ & $5,533 \mathrm{E}+09$ & $1,575 \mathrm{E}+06$ & $9,607 \mathrm{E}+06$ \\
C3 & $15 \%$ & $85 \%$ & $1,849 \mathrm{E}+10$ & $5,533 \mathrm{E}+09$ & $1,575 \mathrm{E}+06$ & $9,646 \mathrm{E}+06$ \\
$\mathrm{C} 4$ & $10 \%$ & $90 \%$ & $1,956 \mathrm{E}+10$ & $5,533 \mathrm{E}+09$ & $1,575 \mathrm{E}+06$ & $9,686 \mathrm{E}+06$ \\
C5 & $5 \%$ & $95 \%$ & $2,064 \mathrm{E}+10$ & $5,533 \mathrm{E}+09$ & $1,575 \mathrm{E}+06$ & $9,725 \mathrm{E}+06$ \\
\hline
\end{tabular}
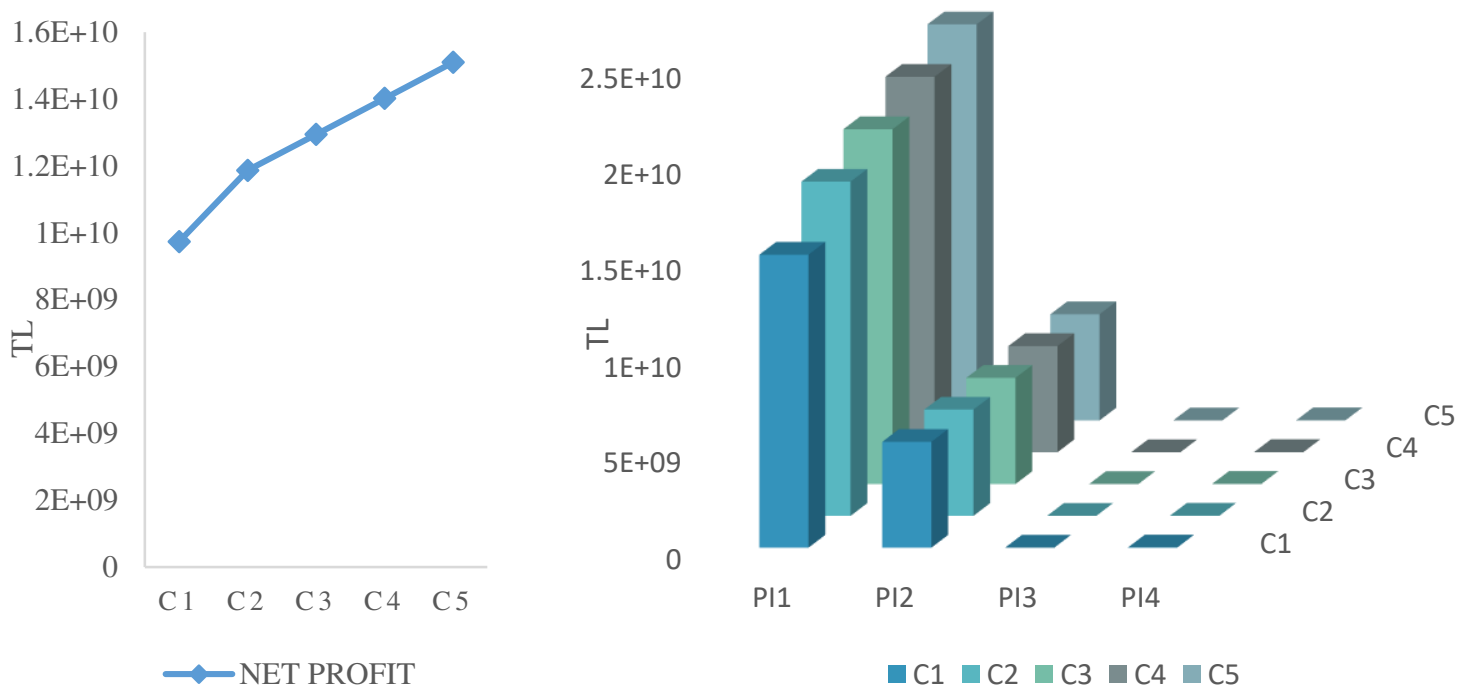

Figure 13 Results according to the Scenario 4

\section{DISCUSSION}

This section includes managerial inferences with regard to the obtained results and how circular economy strategies could be effectively used on a waste PCB supply chain. All inferences are considered specifically for waste PCBs and discussed in relation to the results of the developed network design.

\subsection{Managerial Inferences}

The proposed study has significant operational and strategic contributions for decision-makers and policymakers who are associated with the recycling process of electronic cards. This section focuses on managerial contributions in the framework of the model proposed towards recycling of electronic card wastes. 
Taking these objectives presented in association with the study, actions that could be performed in the managerial sense and for the purpose of policy development are presented below.

- In the supply chain model proposed in line with the Refuse and Rethink objectives, wasting is prevented. Resources that are put into use again continue to stay in the supply chain ecosystem. It may be seen in the proposed network design that these resources are reused as an input for the suppliers. High-level managers need to enlighten all stakeholders regarding this implementation between the manufacturer and the consumer. Such strategies are compatible with circular economy objectives in terms of both minimizing costs and minimizing the damage induced on the environment.

- The Reduce objective exactly overlaps with the outputs of the proposed study. The products that are offered for reused in the supply chain processes reduce the amount of waste. Reduced amount of waste plays a supportive role for environmental sustainability by reducing the damage on the environment. It is seen that, in a structure where environmental policies are constructed on a strategic level, the hybrid supply chain models have a potential to provide direct contributions. In this sense, policy developers need to develop strategies towards making the supply chain approach as applicable as possible for all sectors for more constructive approaches.

- The Reuse, Refurbish and Remanufacture objectives are for diversifying the reuse and usage areas of products that have completed their usage lifespan. In the proposed model, by introducing electronic cards back into the usage process, an input advantage is provided for different sectors. It is vital for decision-makers to adopt a more systematic approach with the clustering method in the recycling ecosystem. With which sectors the sector-based product outputs (waste) could be associated needs to be established accurately. This way, capacity and unavailability costs may be prevented. In addition to this, clustering may provide high profitability by minimizing fixed costs.

- In line with the Repurpose objective, recycled products used for different purposes also contribute to the competitive advantage. In the proposed open-loop supply chain model, secondary users achieve the advantage of accessing products at lower prices and with similar quality. This way, smaller manufacturers in the market may have a competitive advantage in the market. Priority may be given to SMEs with necessary regulations at the point of access to secondary raw materials.

- In the current circular economy environment, the recycling costs are still not on a desired level. There is a need for a more effective management system for recyclable products to be dismantled with lower costs and regained for the economy. In this sense, increasing the number of stakeholders involved in recycling processes may have a cost-reducing effect.

- Based on recycling of electronic cards, the contributions of the hybrid open-loop and closed-loop supply chain model in all sectors in terms of all aspects of sustainability (environmental, economic, social) should be demonstrated. In general, high-level managers focus on the economic aspect. Rather than this, there is a need for a holistic perspective. While the proposed model also focuses more on the economic aspect, the hybrid open-loop and closed-loop supply chain model provide many contributions especially in the environmental sense. In this century where climate change is at the top of the main problems, the environmental aspect has great significance. Moreover, social sustainability should also be considered for a framework where income equality is on a high 
level, and competitive advantage may be achieved. Circular economy creates new fields of work in many respects and allows obtaining recyclable and more inexpensive inputs. This way, a departure point for firms that are trying to find a place in the market may be provided.

\subsection{Assessment of Circular Economy Objectives in the contest of a Waste PCB Supply Chain}

This section firstly explains the circular economy goals which are complementary to each other one by one, and then, inferences proposed in line with these objectives are presented from a supply chain perspective.

While the Refuse (RO) strategy is used by customers and users, it is also used by manufacturers. The Refuse strategy provides a consciousness that makes sense of the concept of circular economy between the manufacturer and the consumer. By directly reducing the need for materials for the relevant product by encouraging development of other products that will provide the same function as the products included in the supply chain, it allows electronic cards to have a longer usage lifespan.

Rethink (R1) is a strategy providing an innovative point of view with a consideration producing value from waste rather than the take-do-dispose understanding of most industrial activities. In this study, rather than repurchasing electronic cards and using them in main products, sharing of recycled products is promoted. The benefits emerging with the adoption of the profitability and circular economy philosophy are also seen in the optimal solution outputs.

With the Reduce (R2) strategy, in addition to promotion of the use of technologies that will increase productivity in the manufacturing process of electronic cards, promotion of fewer resources by supporting modular design approaches is also proposed.

The Reuse (R3) strategy allows the use of PCB parts, which could serve their functions by being made active via the open-loop supply chain but are idle, by other consumers. This way, and additional revenue is obtained, whereas the members of the open-loop supply chain are able to get the products they need with a lower cost and without causing additional use of resources.

The Repair (R4) and Refurbish (R5) strategies show similar effects in the case of PCBs. The facts that electronic cards constitute the semifinished product of WEEE and that electronic card design and manufacturing technology does not allow refurbishing to a significant extent limit the effective use of these two strategies. For these technologies to be used effectively in the future, conducting the manufacturing and design processes of electronic cards compatibly with refurbish and repair will increase productivity.

With the Remanufacture (R6) strategy, parts that have the quality to be used in a new product after dismantling are sent directly to manufacturing by the relevant center. This way, the raw material need in manufacturing is met from the inside of the supply chain with the help of the circular economy approach. Additionally, the materials that are harmful to the environment found in the structures of electronic cards are also eliminated. 
Regarding the Repurpose (R7) strategy, the metal core board coming from the recycling center is dismantled into raw materials such as gold, silver, copper and palladium. The materials extracted from the electronic scrap cards sent to the disassembly center are obtained by open-loop supply chain users. In compliance with the needs of users, these materials are used to produce different products to serve their functions again.

Recycle (R8) is the most important strategy that allows integration of PCBs into a mode with the environmental, social and economic aspects. Examining the results of the model in detail, the highest profitability is obtained after the recycling processes. Furthermore, the recycling ratios, the method used for recycling and reducing the amount of waste are the most important factors that affect the productivity of the network loop. For this reason, by examining the effectiveness of the recycle strategy also with the conducted scenario analyses, its necessity for the case of waste PCB is presented.

While the Recover (R9) strategy may be presented as an effective solution for many recycling processes, it is not used with the same effectiveness in the waste PCB recycling process. A significant part of waste PCBs are used at different stages of the supply chain by recycling. The remaining small amount of waste is disposed of with different methods.

\section{CONCLUSION}

In the scope of this study, by designing a network that dealt with the circular economy perspective and the hybrid open-loop and closed-loop supply chain for recycling of waste PCBs, an optimal solution was searched with a mixedinteger linear programming model. The mixed-integer linear programming (MILP) model was solved in 0,109 seconds with the GAMS program CPLEX solver on the computer with a 1,4 GHz processor and 4GB of RAM. With the developed network design, the lifecycle of PCBs depending on the ratio of the outputs obtained from recycling of waste and high profitability was examined. The objective function value that maximizes profit in network design is $9,712,360,457 \mathrm{TL}$. In the function consists of total revenue ,the total cost of operation, the total cost of fixed facility and the total cost of transportation respectively these values are 15,256,821,148 TL; 5,533,357,058 TL; 1,574,920 TL and 9,528,712 TL. With this study, for the purpose of contributing to the literature, (i) an integrated open-loop and closed-loop supply chain network within the circular economy perspective was modelled by MILP, (ii) a case study was carried out regarding waste PCBs, (iii) the model outputs were associated with sustainability and circular economy objectives. Moreover, in the last part of the study, the sensitivity of the results regarding the changes in the parameters of the centers such as capacity, demand, recycling ratio and unit transportation costs was measured by scenario analyses. In these analyses, the sensitivity of the relevant parameter is computed within the limits set in the range of $5 \%-95 \%$, and managerial inferences were made.

According to the obtained results, product/material flows that affected revenues were among the most important factors affecting profitability. Considering the circular economy objectives, the reuse and repair objective mainly provide revenues for the activities included in the hybrid open-loop and closed-loop supply chain. In this context, it is seen that the CE objectives are applicable for not only closed-loop supply chain models but also open-loop supply chains. The obtained results also supported the idea that the rethink, repurpose, recover and refuse strategies discussed in the scope 
of the study are significant building blocks that make circular economy meaningful. As a result of the scenario analyses, the positive effects of the circular economy strategies on firm profitability were clearly demonstrated. The scope of recycling target demonstrates that, in the second period, 122,616 tons of palladium, 1961,854 tons of copper, 367,848 tons of gold, and 613,079 tons of silver are obtained with chemical operations in the model. Furthermore, the higher recycling ratios, the method used for recycling, and reducing the amount of waste are affected the productivity of the network loop and increased these recycling amounts.

This study also contributes to the literature by considering the gap with an open-loop and closed-loop supply chain network model based on a circular economy perspective regarding the recycling of electronic card waste.Furthermore, this study also contributes to sustainability studies by proposing a model that will protect natural resources and manage recycling flows. It is believed that this study, which presents a thorough model design regarding recycling of waste PCBs and also simultaneously discusses the hybrid model together within the circular economy perspective, will provide a significant contribution for academics, the scientific world and researchers.

Some issues which may be considered in future studies may be listed as: (i) facility selection and assignment problems regarding collection of electronic card wastes, (ii) looking for solutions by deep learning and artificial intelligence applications for waste collection methods, (iii) development of meta-heuristic techniques or technique providing exact results for large-scale problems, (iv) analysis of the closed-loop and open-loop supply chain practices in more specific sectors (automotive, computer, telephone, etc.), (v) analyzing the effects of technologies such as IoT and blockchain emerging with digitalization on supply chain management and a more in-depth analysis of technologies that affect sustainability in the ear of industry 4.0 in this context, (vi) examination of the economic, environmental and social aspects of industry 4.0 technologies on sustainability dimensions and circular economy with actual case analyses.

\section{Declarations}

Funding: The author(s) received no financial support for the research, authorship, and/or publication of this article.

Conflicts of Interest: The authors declare no conflict of interest.

Availability of data and material: The datasets generated during and/or analyzed during the current study are available from the corresponding author on reasonable request.

Code availability: The code generated during and/or analyzed during the current study are available from the corresponding author on reasonable request.

Ethical Approval: Neither the article nor portions of it have been previously published elsewhere. The manuscript has not been submitted to more than one journal for simultaneous consideration.

Consent to Participate: This article does not contain any studies with human participants or animals performed by any of the authors.

Consent to Publish: All authors consent to the publication of the manuscript in Springer, should the article be accepted by the Editor-in-chief upon completion of the refereeing process. 


\section{References}

Accorsi R, Giulia B, RiccardoM (2020) A Closed-Loop packaging network design model to foster infinitely reusable and recyclable containers in food industry. Sustainable Production and Consumption 24: 48-61.

Anna M, Francesco G, Sonia L, Marco F, Maurizio C (2019) Energy and environmental benefits of circular economy strategies: the case study of reusing used batteries from electric vehicles. Journal of Energy Storage 25: 100845.

Awasthi AK, Zlamparet GI, Zeng X, Li J (2017) Evaluating waste printed circuit boards recycling: Opportunities and challenges, a mini review. Waste Management and Research. 35(4): 346-356.

Baldé CP, Forti V, Gray V, Kuehr R, Stegmann P (2017) The global e-waste monitor 2017: Quantities, flows and resources. United Nations University, International Telecommunication Union, and International Solid Waste Association.

Brydges, T (2021) Closing the loop on take, make, waste: Investigating circular economy practices in the Swedish fashion industry. Journal of Cleaner Production 293:126245.

Cole C, Gnanapragasam A, Singh J, Cooper T (2018) Enhancing reuse and resource recovery of electrical and electronic equipment with reverse logistics to meet carbon reduction targets. Procedia CIRP 69: 980-985.

Deschamps J Simon B, Tagnit-Hamou A, Amor B (2018) Is open-loop recycling the lowest preference in a circular economy? Answering through LCA of glass powder in concrete. Journal of Cleaner Production 185: 14-22.

Deveci H (2016) Atık baskılı devre kartlarının ekonomik potansiyeli ve çevresel karakterizasyonu. Bilimsel Madencilik Dergisi 55(3): 35-44.

Ene S, Öztürk N (2014) Open-Loop reverse supply chain network design. Procedia Social and Behavioral Sciences 109: $1110-1115$.

Fornasiero R, Brondi C, Fragassi, F(2016) Sustainable networks for WEEE treatment: A case study. Procedia CIRP 41: 276-281.

Gautam A, Shankar R, Vrat P (2021) End-of-life solar photovoltaic e-waste assessment in India: a step towards a circular economy. Sustainable Production and Consumption 26:65-77. https://doi.org/10.1016/j.spc.2020.09.011

Govindan K, Soleimani H, Kannan D (2015) Reverse logistics and closed-loop supply chain: A comprehensive review to explore the future. European Journal of Operational Research 240(3):603-626.

Ha KH (2012) Identification by thermal analysis for open-loop recycling of post-consumer waste polypropylene to apply refrigerator plastics. Materials and Design (1980-2015) 36: 359-365. https://doi.org/10.1016/j.matdes.2011.11.037

Halonen N, Majuri M, Lanz, M (2019) Characteristics of a circular economy framework to support strategic renewal in manufacturing firms. Procedia CIRP 81: 653-658. https://doi.org/10.1016/j.procir.2019.03.171

Hanumante NC, Shastri Y, Hoadley A (2019) Assessment of circular economy for global sustainability using an integrated model. Resources, Conservation and Recycling 151: 104460. https://doi.org/10.1016/j.resconrec.2019.104460

Hao S, Kuah ATH, Rudd CD, Wong KH, Lai NYG, Mao J, Liu, X (2020) A circular economy approach to green energy: Wind turbine, waste, and material recovery. Science of the Total Environment 702: 
135054.https://doi.org/10.1016/j.scitotenv.2019.

Huysman S, Debaveye S, Schaubroeck T, De Meester S, Ardente F, Mathieux F, Dewulf J (2015) The recyclability benefit rate of closed-loop and open-loop systems: A case study on plastic recycling in Flanders. Resources, Conservation and Recycling 101: 53-60.

Huysveld S, Hubo S, Ragaert K, Dewulf J (2019) Advancing circular economy benefit indicators and application on open-loop recycling of mixed and contaminated plastic waste fractions. Journal of Cleaner Production 211: 113. https://doi.org/10.1016/j.jclepro.2018.11.110

Ismail H, \& Marlia MH (2020) A review of sustainable e-waste generation and management: present and future perspectives. Journal of Environmental Management, 264: 110495.

Jadhao PR, Ahmad E, Pant KK, Nigam KDP (2020) Environmentally friendly approach for the recovery of metallic fraction from waste printed circuit boards using pyrolysis and ultrasonication. Waste Management. 118: 150160.

Kalverkamp M (2018) Hidden potentials in open-loop supply chains for remanufacturing. The International Journal of Logistics Management 29(4): 1125-1146. https://doi.org/10.1108/IJLM-10-2017-0278.

Kalverkamp M, Young SB (2019) In support of open-loop supply chains : Expanding the scope of environmental sustainability in reverse supply chains. Journal of Cleaner Production 214: 573-582. https://doi.org/10.1016/j.jclepro.2019.01.006

Komly C, Azzaro-pantel C, Hubert A, Pibouleau L, Archambault V (2012) Resources , Conservation and Recycling Multiobjective waste management optimization strategy coupling life cycle assessment and genetic algorithms : Application to PET bottles. Resources, Conservation and Recycling 69: 66-81. https://doi.org/10.1016/j.resconrec.2012.08.008.

Mohan TVK, Amit RK (2021) Modeling oligopsony market for end-of-life vehicle recycling. Sustainable Production and Consumption 25: 325-346. https://doi.org/10.1016/j.spc.2020.09.001

Larrain M, Van Passel S, Thomassen G, Kresovic U, Alderweireldt N, Moerman E, Billen P (2020) Economic performance of pyrolysis of mixed plastic waste: Open-loop versus closed-loop recycling. Journal of Cleaner Production 270: 122442

Liu Q, Hu T (2017) he Life Cycle Evaluation Model of External Diseconomy of Open-loop Supply Chain. In: IOP Conference Series: Earth and Environmental Science. IOP Publishing 81(1): 012052. https://doi.org/10.1088/1755-1315/81/1/012052

Maisel F, Perrine C, Gergana D, Johanna E, Nils FN, Martin, S-R (2020) Preparing WEEE plastics for recycling how optimal particle sizes in pre-processing can improve the separation efficiency of high quality plastics. Resources, Conservation \& Recycling, 154: 104619.

Milnes E, Perrochet P (2013) Assessing the impact of thermal feedback and recycling in open-loop groundwater heat pump (GWHP) systems: a complementary design tool. Hydrogeology Journal 21(2): 505-514. https://doi.org/10.1007/s10040-012-0902-y.

Moktadir MA, Rahman T, Rahman MH, Ali SM, Paul SK (2018) Drivers to sustainable manufacturing practices and circular economy: A perspective of leather industries in Bangladesh. Journal of Cleaner Production 174: 13661380. https://doi.org/10.1016/j.jclepro.2017.11.063 
Nakamura S, Kondo Y, Kagawa S, Matsubae K, Nakajima K, Nagasaka T (2014) MaTrace: Tracing the fate of materials over time and across products in open-loop recycling. Environmental Science and Technology 48(13): 7207-7214. https://doi.org/10.1021/es500820h

Nicholson AL, Olivetti EA, Gregory JR, Field FR, Kirchain RE (2009) End-of-life LCA allocation methods: OpenLoop recycling impacts on robustness of material selection decisions. In: 2009 IEEE International Symposium on Sustainable Systems and Technology. IEEE, pp 1-6. https://doi.org/10.1109/ISSST.2009.5156769

Ning C, Sze C, Lin K, Chi D, Hui W, Mckay G (2017) Waste printed circuit board (PCB) recycling techniques. Topics in Current Chemistry 375(2): 1-36.

Özceylan E (2016) Simultaneous optimization of closed-and open-loop supply chain networks with common components. Journal of Manufacturing Systems 41: 143-156.

Özceylan E, Paksoy T, Bektaş T (2014) Modeling and optimizing the integrated problem of closed-loop supply chain network design and disassembly line balancing. Transportation Research Part E: Logistics and Transportation Review 61: 142-164. https://doi.org/10.1016/j.tre.2013.11.001

Özkan A (2018) Atık baskılı devre kartlarından değerli metal geri kazanım yöntemlerinin çok ölçütlü karar verme teknikleri ile değerlendirilmesi. Afyon Kocatepe Üniversitesi Fen Ve Mühendislik Bilimleri Dergisi 18(2): 529537.

Parida V, Burström T, Visnjic I, Wincent J (2019) Orchestrating industrial ecosystem in circular economy: A twostage transformation model for large manufacturing companies. Journal of Business Research 101: 715-725. https://doi.org/10.1016/j.jbusres.2019.01.006

Pishvaee MS, Rabbani M, Torabi SA (2011) A robust optimization approach to closed-loop supply chain network design under uncertainty. Applied Mathematical Modelling 35(2): 637-649.

Potting J, Hekkert M, Worrell E, Hanemaaijer A (2017) Circular Economy: Measuring Innovation in the Policy Report. PBL Netherlands Environmental Assessment Agency: The Hague, The Netherlands pp 1-46.

Sehnem S., Vazquez-brust D, Carla S, Pereira F (2019) Circular economy : benefits, impacts and overlapping. Supply chain management: An International Journal 6: 784-804.

Tan Q, Liu L, Yu M, Li J (2020) An innovative method of recycling metals in printed circuit board (PCB) using solutions from PCB production. Journal of Hazardous Materials 390: 121892.

Tseng ML, Lin RJ, Lin YH, Chen RH, Tan K (2014) Close-loop or open hierarchical structures in green supply chain management under uncertainty. Expert Systems with Applications 41(7): 3250-3260.

Tseng M, Chiu ASF, Liu G, Jantaralolica T (2020) Circular economy enables sustainable consumption and production in multi- level supply chain system. Resource Conservation and Recycling 154: 104601.

Velenturf AP, Archer SA, Gomes HI, Christgen B, Lag-Brotons AJ, Purnell, P (2019) Circular economy and the matter of integrated resources. Science of the Total Environment 689: 963-969. https://doi.org/10.1016/j.scitotenv.2019.06.449

Wagner F, Peeters JR, De Keyzer J, Janssens K, Duflou JR, Dewulf W(2019) Towards a more circular economy for WEEE plastics-Part A: Development of innovative recycling strategies. Waste Management 100: 269-277.

Williams S, Robinson J (2020) Measuring sustainability: An evaluation framework for sustainability transition experiments. Environmental Science and Policy 103: 58-66. https://doi.org/10.1016/j.envsci.2019.10.012 
Wu C, Hu M, Ni F (2021) Supporting a circular economy : Insights from Taiwan's plastic waste sector and lessons for developing countries. Sustainable Production and Consumption 26 : 228-238. https://doi.org/10.1016/j.spc.2020.10.009

Yamane LH, de Moraes VT, Espinosa DCR, Tenório JAS (2011) Recycling of WEEE: characterization of spent printed circuit boards from mobile phones and computers. Waste Management 31(12): 2553-2558.

Yao Y, Bai Q, He J, Zhu L, Zhou K, Zhao Y (2020) Reverse flotation efficiency and mechanism of various collectors for recycling waste printed circuit boards. Waste Management 103: 218-227.

Zlamparet GI, Ijomah W, Miao, Y, Awasthi AK, Zeng X, Li J (2017) Remanufacturing strategies: A solution for WEEE problem. Journal of Cleaner Production 149:126-136. 


\section{APPENDIX}

\section{Nomenclature}

\section{Notations}

The formulation for the mixed-integer model developed in light of the above information is given below.

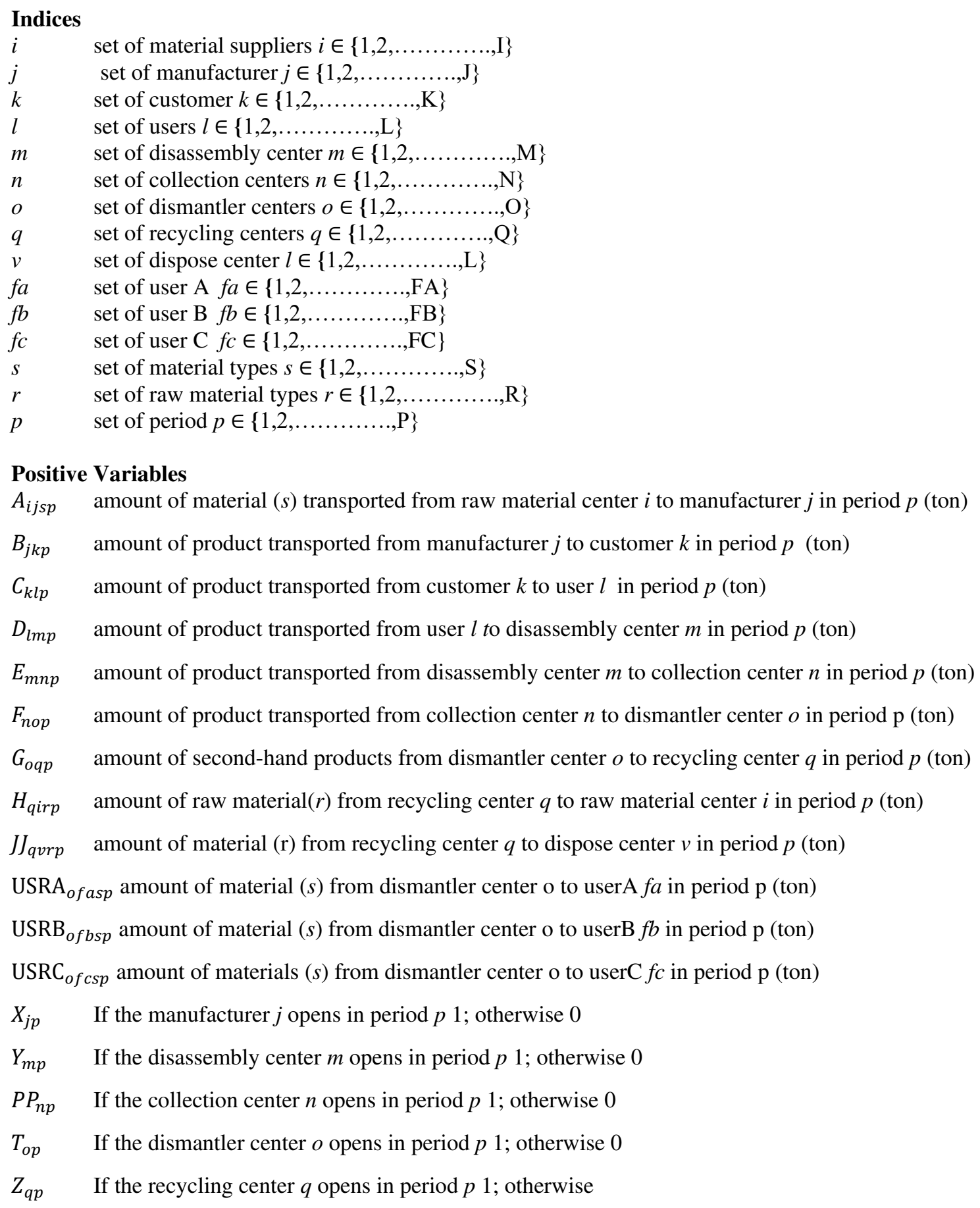




\section{Parameters}

$e_{i s p} \quad$ material capacity $(s)$ of material supplier $i$ in period $p$

$t_{j p} \quad$ manufacturer $j$ of capacity in period $p$

$z_{k p} \quad$ the demand of customer $k$ in period $p$

$n_{l p} \quad$ the demand of user $l$ in period $p$

$a_{m p} \quad$ disassembly center $m$ of capacity in period $p$

$q_{n p} \quad$ collection center $n$ of capacity in period $p$

$b_{o p} \quad$ dismantler center $o$ of capacity in period $p$

$c_{q r p} \quad$ recycling center $q$ of material capacities $(r)$ in period $p$

$a a_{\text {fasp }}$ userA $f a$ of material capacities $(s)$ in period $p$

$b b_{f b s p} \quad$ userB $f b$ of material capacities $(s)$ in period $p$

$c c_{f c s p} \quad$ userC $f c$ of material capacities $(s)$ in period $p$

$\Delta_{i j} \quad$ distance between supplier $i$ and manufacturer $\mathrm{j}(\mathrm{km})$

$\Delta_{j k} \quad$ distance between manufacturer $\mathrm{j}$ and customer $k(\mathrm{~km})$

$\Delta_{k l} \quad$ distance between customer $k$ and user $l(\mathrm{~km})$

$\Delta_{l m} \quad$ distance between user $l$ and disassembly center $m(\mathrm{~km})$

$\Delta_{m n} \quad$ distance between disassembly center $m$ and collection center $n(\mathrm{~km})$

$\Delta_{n o} \quad$ distance between collection center $n$ and dismantler center $o(\mathrm{~km})$

$\Delta_{q i} \quad$ distance between recycling center $q$ and material supplier center $i(\mathrm{~km})$

$\Delta_{\text {of } a} \quad$ distance between dismantler center $o$ and user $f a(\mathrm{~km})$

$\Delta_{o f b} \quad$ distance between dismantler center $o$ and user $f b(\mathrm{~km})$

$\Delta_{\text {ofc }} \quad$ distance between dismantler center $o$ and user $f c(\mathrm{~km})$

$U_{i s p} \quad$ purchasing cost from material $i$ of material $s$ in period $p($ TL/ton)

$\alpha_{j p} \quad$ manufacturing cost $o f$ manufacturer $j$ in period $p$ (TL/ton)

$V_{k p} \quad$ purchasing cost of customer in period $p$ (TL/ton)

$W_{l p} \quad$ purchasing cost of user in period $p$ (TL/ton)

$\gamma_{m p} \quad$ operation cost of disassembly center $m$ in period $p$ (TL/ton)

$\theta_{n p} \quad$ operation cost of collection center $n$ in period $p$ (TL/ton)

$\beta_{o p} \quad$ operation cost of dismantler center $o$ in period $p$ (TL/ton)

$K_{\text {qrp }} \quad$ operation cost of raw material $r$ in recycling center $q$ in period $p$ (TL/ton)

cc transportation cost (TL/ $/ \mathrm{km} *$ ton)

ws the ratio of the weight of one-pieces to the total weight of the product (ton)

$w r \quad$ the ratio of the weight of the semi-finished product (ton)

$d d_{\text {osp }} \quad$ purchasing cost from dismantler center $o$ of material $s$ in period $p$ for userA (TL/ton)

$e e_{o s p} \quad$ purchasing cost from dismantler center $o$ of material $s$ in period $p$ for userB (TL/ton) 
$g g_{\text {osp }} \quad$ purchasing cost from dismantler center $o$ of material $s$ in period $p$ for userC (TL/ton)

$f_{j p} \quad$ fixed facility cost of manufacturer $j$ in period $p$ (TL/ton)

$f_{m p} \quad$ fixed facility cost of disassembly center $m$ in period $p$ (TL/ton)

$f_{n p} \quad$ fixed facility cost of collection center $n$ in period $p$ (TL/ton)

$f_{o p} \quad$ fixed facility cost of dismantler center $o$ in period $p$ (TL/ton)

$f_{q p} \quad$ fixed facility cost of recycling center $q$ in period $p$ (TL/ton)

$L_{P} \quad$ the largest number of the manufacturer in period $p$

$N_{P} \quad$ the largest number of disassembly center in period $p$

$R_{P} \quad$ the largest number of collection center in period $p$

$Z Z_{P} \quad$ the largest number of dismantler center in period $p$

$S_{P} \quad$ the largest number of a recycling center in period $p$

$\mu \quad$ percentage of material sent from dismantler centers to recycling centers

$\omega$ percentage of material sent from dismantler center to user A

$\varphi \quad$ percentage of material sent from dismantler center to user B

$l l$ percentage of material sent from dismantler center to user $\mathrm{C}$

$t t \quad$ percentage of material sent from dismantler center to dispose center

$t z \quad$ percentage of raw material separated from the recycling center 


\section{Supplementary Files}

This is a list of supplementary files associated with this preprint. Click to download.

- GraphicalAbstract.docx 